\title{
Evaluation of Structure-Function Relationships of Aggregation-Induced Emission Luminogens for Simultaneous Dual Applications of Specific Discrimination and Efficient Photodynamic Killing of Gram-Positive Bacteria
}

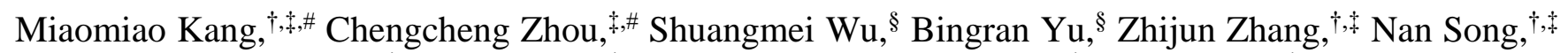
Michelle Mei Suet Lee, ${ }^{\ddagger}$ Wenhan Xu ${ }^{\ddagger}$ Fu-Jian Xu, ${ }^{\S}$ Dong Wang, ${ }^{*},{ }^{\dagger}$ Lei Wang, ${ }^{* \dagger}$ and Ben Zhong Tang*,

${ }^{+}$Center for AIE Research, College of Materials Science and Engineering, Shenzhen University, Shenzhen 518060, China.

${ }^{\ddagger}$ Hong Kong Branch of Chinese National Engineering Research Center for Tissue Restoration and Reconstruction, Department of Chemistry, Institute of Molecular Functional Materials, State Key Laboratory of Neuroscience, Division of Biomedical Engineering and Division of Life Science, The Hong Kong University of Science and Technology, Clear Water Bay, Kowloon, Hong Kong 999077, China.

${ }^{s}$ Key Laboratory of Biomedical Materials of Natural Macromolecules (Beijing University of Chemical Technology), Ministry of Education, Beijing Laboratory of Biomedical Materials, Beijing University of Chemical Technology, Beijing 100029, China.

\section{Table of Contents}

Materials and Methods $\quad$ S3

$\begin{array}{ll}\text { Synthesis and Characterization } & \text { S7 }\end{array}$

$\begin{array}{ll}\text { Figure S1. The synthetic routes of AIEgens. } & \text { S7 }\end{array}$

Figure S2. ${ }^{1} \mathrm{H}$ NMR spectra of TPy. $\quad$ S10

Figure S3. ${ }^{13} \mathrm{C}$ NMR spectra of TPy. $\quad$ S10

Figure S4. HRMS spectrum of TPy. $\quad$ S11

Figure S5. ${ }^{1} \mathrm{H}$ NMR spectra of TPPy. $\quad$ S11

Figure S6. ${ }^{13} \mathrm{C}$ NMR spectra of TPPy. $\quad S 12$

$\begin{array}{ll}\text { Figure S7. HRMS spectrum of TPPy. } & \text { S12 }\end{array}$

Figure S8. ${ }^{1} \mathrm{H}$ NMR spectra of MeOTTPy. $\quad$ S13

Figure 59. ${ }^{13} \mathrm{C}$ NMR spectra of MeOTTPy. $\quad$ S13

$\begin{array}{ll}\text { Figure S10. HRMS spectrum of MeOTTPy. } & \text { S14 }\end{array}$

Figure S11. ${ }^{1} \mathrm{H}$ NMR spectra of Compound $\mathbf{5} . \quad$ S14

Figure S12. ${ }^{13} \mathrm{C}$ NMR spectra of Compound $5 . \quad S 15$

Figure S13. HRMS spectrum of Compound 5. S15

Figure S14. ${ }^{1} \mathrm{H}$ NMR spectra of TPE-TTPy. $\quad$ S16

Figure S15. ${ }^{13} \mathrm{C}$ NMR spectra of TPE-TTPy. $\quad$ S16

$\begin{array}{ll}\text { Figure S16. HRMS spectrum of TPE-TTPy. } & \text { S17 }\end{array}$ 
Figure S17. Size distribution of the aggregates of TPy, TPPy, TTPy and TPE-TTPy.

Figure S18. Frontier molecular orbitals for AIEgens.

Figure S19. Bacteria staining and imaging of AIEgens.

Figure S20. Gram-positive bacteria staining and imaging of AIEgens.

Figure S21. Gram-positive bacteria staining and imaging of AIEgens. $\quad$ S19

Figure S22. Selective Gram-positive bacteria imaging of AIEgens in bacteria mixtures. S20

Figure S23. Selective Gram-positive bacteria imaging of TTPy in bacteria mixtures. S20

$\begin{array}{lr}\text { Figure S24. Photostability of TTPy and HI. } & \text { S21 }\end{array}$

Figure S25. Light-induced ROS generation of AIEgens monitored by DCFH. S21

$\begin{array}{lr}\text { Figure S26. ROS generation of TTPy, HI and Ce6. } & \text { S22 }\end{array}$

Figure S27. Photodynamic antibacterial activity of TTPy on S. epidermidis. $\quad$ S22

Figure S28. Photodynamic antibacterial activity of HI on S. aureus. $S 23$

Figure S29. Photodynamic antibacterial activity of Ce6 on S. aureus. $S 23$

$\begin{array}{lr}\text { Table S1. Properties of AIEgens. } & \text { S24 }\end{array}$

$\begin{array}{ll}\text { References } & \text { S24 }\end{array}$ 


\section{Materials and Methods}

Materials: Six kinds of microorganisms including four Gram-positive bacteria (Staphylococcus aureus (S. aureus, ATCC6538), Enterococcus faecalis (E.faecalis, JCM5803), Bacillus subtilis (B. subtilis, NCBI 3610) and Staphylococcus epidermidis (S. epidermidis, ATCC12228)), two Gram-negative bacteria (Escherichia coli (E. coli, ATCC25922) and Pseudomonas aeruginosa (P. aeruginosa, JCM5962)) were purchased from Beijing Bio-Med Technology Development Co., Ltd. and China General Microbiological Culture Collection Center. LB, NB and TSB were purchased from USB Co. $1 \times$ PBS (pH 7.4) used throughout the work was purchased from Thermo Fisher Scientific. 2',7'-dichlorodihydrofluorescein diacetate (DCFH-DA) and 9,10-anthracenediyl-bis(methylene) dimalonic acid (ABDA) were purchased from Sigma-Aldrich. Hexidium Iodide (HI) was purchased from AAT Bioquest. Chlorin e6 (Ce6) was purchased from J\&K. 4-(diphenylamino)benzaldehyde, 4-bromo-N,N-diphenylaniline, 4-bromo-N,N-bis(4-Methoxyphenyl)aniline, (4-formylphenyl) boronic acid, (5-formylthiophen-2-yl)boronic acid, $\mathrm{Pd}(\mathrm{dppf}) \mathrm{Cl}_{2}$, piperidine, 4-methylpyridine and iodomethane were purchased from J\&K or Meryer. All the chemicals used as supplied without further purification. Tetrahydrofuran (THF) was dried by distillation using sodium as drying agent and benzophenone as indicator. Intermediate compounds 1, 2, 3, and 4 were synthesized according to the literature method ${ }^{1,2}$.

Characterization: ${ }^{1} \mathrm{H}$ and ${ }^{13} \mathrm{C}$ NMR spectra were recorded on a Bruker ARX 400 NMR spectrometer using DMSO- $d_{6}$ as internal reference. High-resolution mass spectra (HRMS) were obtained on a Finnigan MAT TSQ 7000 Mass Spectrometer operating in a MALDI-TOF mode. Quantum yield was determined by a Quanta-integrating sphere. Absorption spectra were measured on a Milton Ray Spectronic 3000 array spectrophotometer. Steady-state photoluminescence (PL) spectra were recorded on a Perkin Elmer LS 55 spectrometer and Edinburgh FS5 fluorescence spectrophotometer. Fluorescence images were collected on a fluorescence microscope (Upright Biological Microscope Ni-U). Laser confocal scanning microscopy images were collected on confocal laser scanning microscope (FV1200-IX83, Olympus, Japan; ZEISS LSM 800). The bacterial morphology was investigated using Scanning Electron Microscopy (Hitachi S4800, Japan). Particle size analyses were implemented using a Zetasizer Nano ZSP (Malvern NanoZSP+MPT-2). $\zeta$-potential measurements were operated with Nano ZS (ZEN3600).

ROS Detection in Solution: A commonly used ROS indicator DCFH-DA was utilized to detect the ROS generation of AIEgens in solution under white light irradiation $\left(22.1 \mathrm{~mW} \mathrm{~cm}^{-2}\right)$. Briefly, $0.5 \mathrm{~mL}$ DCFH-DA in ethanol $\left(1 \times 10^{-3} \mathrm{M}\right)$ was added to $2 \mathrm{~mL} 1 \times 10^{-2} \mathrm{M} \mathrm{NaOH}$ and allowed to stir at room temperature for 30 min. Then the hydrolysate was neutralized with $10 \mathrm{~mL}$ of $1 \times \mathrm{PBS}$ at $\mathrm{pH} 7.4$, and kept in dark until use. By the time, DCFH-DA was hydrolyzed to DCFH. Then the ROS indicator $\left(4 \times 10^{-5} \mathrm{M}\right)$ in PBS was further 
diluted to $1 \times 10^{-5} \mathrm{M}$ or $5 \times 10^{-6} \mathrm{M}$ in the sample solution of AlEgens $\left(5 \times 10^{-8} \mathrm{M}\right.$ or $\left.1 \times 10^{-6} \mathrm{M}\right)$ for measurement by PL instrument (Edinburgh FS5 fluorescence spectrophotometer). The fluorescence of 2', 7'-dichlorofluorescein triggered by AIEgens-sensitized ROS under white light irradiation were measured at different time intervals. The PL spectra were measured with excitation at $488 \mathrm{~nm}$ and emission was collected from 490 to $600 \mathrm{~nm}$. ABDA was used as another indicator to evaluate the singlet oxygen generation ability of the PSs under white light irradiation. ABDA $\left(5 \times 10^{-5} \mathrm{M}\right)$ solution was mixed with the PSs in water $\left(5 \times 10^{-6}\right.$ M) and then was exposed to white light irradiation $\left(22.1 \mathrm{~mW} \mathrm{~cm}^{-2}\right)$. The absorbance decrease of ABDA at $378 \mathrm{~nm}$ was recorded at various irradiation time.

Bacteria Culture and Preparation of Bacteria Solution for Staining: A single bacteria colony on solid agar plate was transferred to $10 \mathrm{~mL}$ corresponding liquid culture medium and grown for $6 \sim 8 \mathrm{~h}$ at $37^{\circ} \mathrm{C}$ with a shaking speed of $200 \mathrm{rpm}$ (Culture medium: LB for E. coli, P. aeruginosa, B. subtilis and S. epidermidis, NB for S. aureus and TSB for E. faecalis). Bacteria were harvested by centrifuging at $7100 \mathrm{rpm}$ for $2 \mathrm{~min}$, and then washed by PBS two times. After removal of the supernatant, the remaining bacteria were resuspended with PBS, and diluted to an optical density of 1.0 at $600 \mathrm{~nm}\left(\mathrm{OD}_{600}=1.0\right.$ with about $\left.10^{8} \mathrm{CFU} \mathrm{mL}^{-1}\right)$.

Bacteria Staining and Imaging: $500 \mu \mathrm{L}$ bacteria $\left(\mathrm{OD}_{600}=1.0\right)$ in a $1.5 \mathrm{~mL}$ centrifuge tube were harvested by centrifuging ( $7100 \mathrm{rpm}, 2 \mathrm{~min}$ ). Then the supernatant was removed, $50 \mu \mathrm{L}$ of $2 \mu \mathrm{M}$ AIEgen in PBS solutions were added, and incubated for $20 \mathrm{~min}$ at ambient temperature after dispersing with a vortex. About $2 \mu \mathrm{L}$ of the stained bacteria solution was transferred to a glass slide, and then covered by a coverslip for imaging. The image of E. coli and S. aureus was collected under an FL microscope (Upright Biological Microscope Ni-U) with the following settings: excitation filter $=460-490 \mathrm{~nm}$, dichroic mirror $=505 \mathrm{~nm}$, emission filter $=515 \mathrm{~nm}$ long pass; for the P. aeruginosa and E. faecalis imaging, confocal images were captured by using CLSM (FV1200-IX83, Olympus, Japan) with excitation at $488 \mathrm{~nm}$ and emission was collected from 530 to $700 \mathrm{~nm}$; for B. subtilis, S. epidermidis and bacteria mixtures, confocal images were captured by using CLSM (ZEISS LSM 800) with excitation at $488 \mathrm{~nm}$ and emission was collected from 500 to $700 \mathrm{~nm}$.

Photostability of TTPy and HI: The dye-labelled S. aureus were imaged by a confocal microscope (ZEISS LSM 800) with the excitation at $488 \mathrm{~nm}$ ( $2 \%$ laser power).

ל-potential measurements: Bacteria were incubated with AIEgens for $20 \mathrm{~min}$ at ambient temperature, respectively. The samples were harvested by centrifuging ( $7100 \mathrm{rpm}, 2 \mathrm{~min}$ ), resuspended in $\mathrm{H}_{2} \mathrm{O}$ and then placed on ice for Zeta potential measurements with Nano ZS (ZEN3600). The bacteria without AIEgens were also treated under the same conditions as control.

Assessment of Antibacterial Activity: The antimicrobial activities of AIEgen, $\mathrm{HI}$ and Ce6 to bacteria were 
evaluated by traditional surface plating method. For the antibacterial activity of TTPy in dark, PBS solution of E. coli or S. aureus $\left(\sim 2 \times 10^{7} \mathrm{CFU} \mathrm{mL}^{-1}\right)$ was treated with TTPy $\left(2 \times 10^{-6} \mathrm{M}\right)$ for 20 min at $37{ }^{\circ} \mathrm{C}$, respectively. Next, the bacteria suspensions were serially diluted by $10^{4}$-fold with PBS. $100 \mu \mathrm{L}$ diluted bacteria were spread on the corresponding solid agar plate, and then incubated for $14-16 \mathrm{~h}$ at $37^{\circ} \mathrm{C}$. The antibacterial activity of the TTPy on the bacteria were evaluated according to the reduced ratio of colonies. The bacteria colonies on the agar plates were counted and the reduced ratio was calculated based on the equation $[(\mathrm{A}-\mathrm{B}) / \mathrm{A}] \times 100 \%$, where $\mathrm{A}$ is the mean number of bacteria colonies in the control sample (without AIEgen), and B is the mean number of bacteria after incubated with the AIEgen. The results were repeated for three times. As to antibacterial activity of AIEgen under light, the bacteria were treated under the same conditions as the experiment in the dark except for that the samples were incubated for 5 min in the dark and then irradiated under white light $\left(60 \mathrm{~mW} \mathrm{~cm}^{-2}\right)$ for $15 \mathrm{~min}$. For $\mathrm{HI}$ and $\mathrm{Ce} 6$, the method was the same to TTPy.

Scanning Electron Microscopy (SEM) Measurement: SEM was applied to observe the morphologies of bacteria before and after treated with TTPy. After the treatment described in the antibacterial experiments above, bacteria were immediately fixed with $0.5 \%$ glutaraldehyde PBS solution at ambient temperature for $30 \mathrm{~min}$. Then bacteria were centrifuged at $4{ }^{\circ} \mathrm{C}(7100 \mathrm{rmp}$ for $5 \mathrm{~min})$, followed by removing the supernatant and resuspending the remaining bacteria in sterile water. $2 \mu \mathrm{L}$ of bacteria solution was dropped on clean silicon slices and naturally dried. Next, for further fixing bacteria, $0.1 \%$ glutaraldehyde was added for $1 \mathrm{~h}$, and $0.5 \%$ glutaraldehyde for another $1 \mathrm{~h}$. Then the specimens were washed for three times with sterile water, dehydrated by different content of ethanol (70\% for $6 \mathrm{~min}, 90 \%$ for $6 \mathrm{~min}$, and 100\% for $6 \mathrm{~min}$ ), and then dried in vacuum drying oven. The specimens were coated with platinum before SEM observation (Hitachi S4800, Japan).

In Vivo Anti-Infection Assay: Normal 6-8 week male Wistar rats purchased from Beijing Vital River Laboratory Animal Technology Co. Ltd., China) were used in the in vivo experiments. All protocols involving the mice comply with the guidelines described in the Association for Assessment and Accreditation of Laboratory Animal Care, approved by the Peking University Health Centre Institutional Animal Care and Use Committee and Peking University Health Centre Ethnics Committee.

16 of Wistar rats were randomly divided into four groups: (1) bacteria-infected group with TTPy and white light irradiation treatment; (2) bacteria-infected group with TTPy alone treatment; (3) bacteria-infected group with no treatment; (4) control group without bacterial infection. The rats were anesthetized by intraperitoneal injection of $4 \%$ pentobarbital sodium. Then, two $1.5 \times 1.5 \mathrm{~cm}^{2}$ open excision wounds were prepared on each rat by removing the dorsal flank skin on both sides of the spine. The 
bacteria-infected wound models were established by inoculating $50 \mu \mathrm{L}$ of $S$. aureus suspension $\left(2 \times 10^{8} \mathrm{CFU}\right.$ $\left.\mathrm{mL}^{-1}\right)$ over each wound on rats. For the groups with TTPy treatment, $50 \mu \mathrm{L}$ of TTPy $(4 \mu \mathrm{M})$ was then added onto each wound and covered with sterile nonwoven fabrics for $20 \mathrm{~min}$. Subsequently, the wounds were irradiated by white light with a power density of $60 \mathrm{~mW} \mathrm{~cm}{ }^{-2}$ for $30 \mathrm{~min}$ or not. The operation of TTPy injection and white light irradiation were performed once a day for sustained four days. The wound regions were imaged by camera on day 1 and day 4 post-infection. All mice were sacrificed and the entire wound with adjacent normal skin were harvested on the day 4 post-infection. To determine the amount of the bacteria in the infectious tissues of the rats, the infectious tissues were separated and homogenized in normal saline and then were diluted 1000 times with normal saline. $20 \mu \mathrm{L}$ of the diluted bacteria solution was sprayed onto LB agar plate and subjected to culturing at $37^{\circ} \mathrm{C}$. After $24 \mathrm{~h}$, the bacterial colonies on the plate were counted for analysis. The other tissues were fixed in $4 \%$ paraformaldehyde for the histological analysis.

Histological Examination: The collected tissues were fixed in $4 \%$ paraformaldehyde for the histological analysis, and then embedded in paraffin. The fixed tissues were cut into slices with a thickness of $4 \mathrm{~mm}$. Next, $\mathrm{H} \& \mathrm{E}$ staining was carried out according to the standard protocols as described in the previous work ${ }^{3}$.

Data analysis: The investigators were not blinded to the group allocation. Quantitative data were expressed as mean \pm standard deviation (s.d.). Statistical comparisons were made by unpaired Student's t-test between two groups. $P$ value $<0.05$ was considered statistically significant. The Origin 9.0 software was used for graph plotting. Each experiment included at least three replicates. 


\section{Synthesis and Characterization}

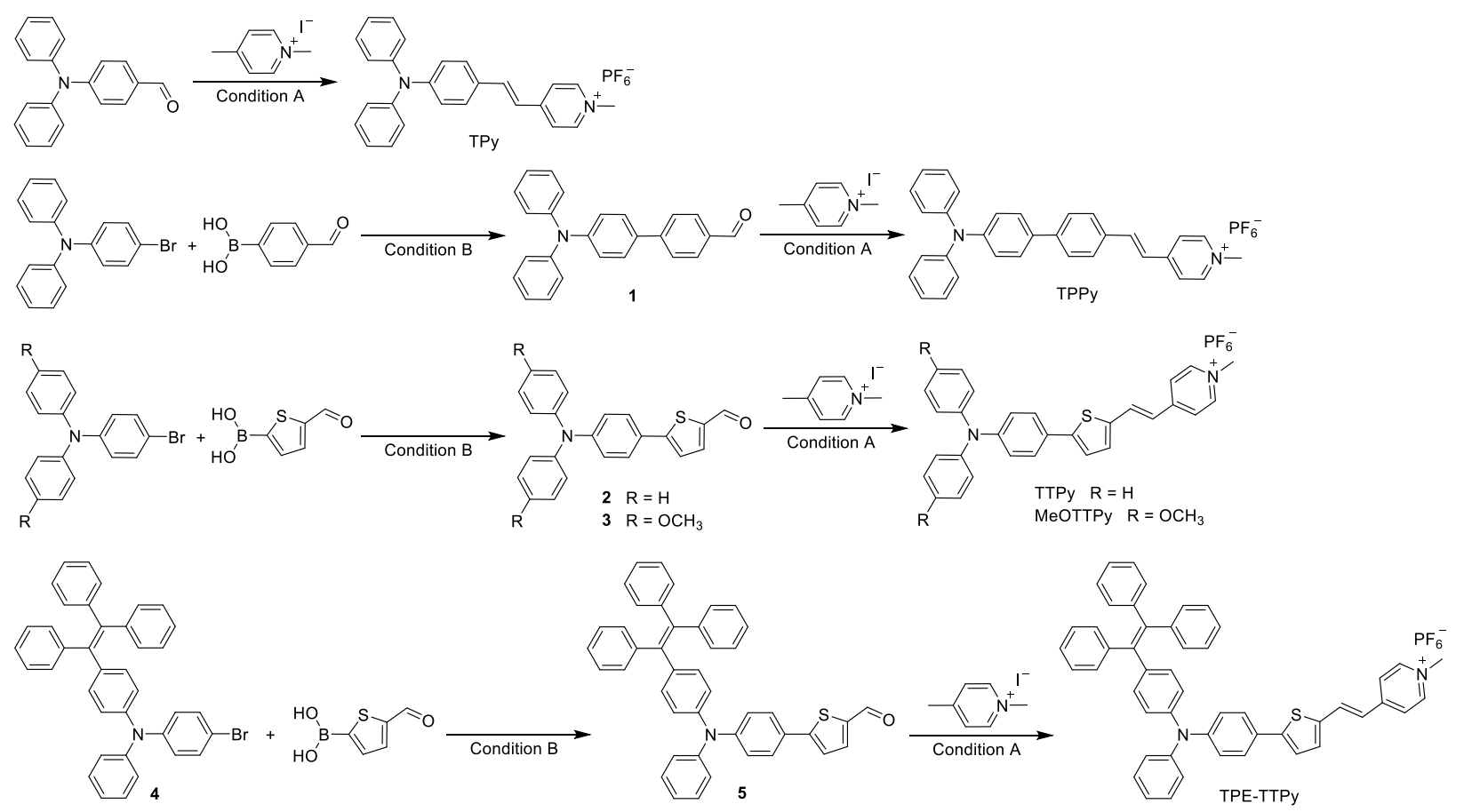

Figure S1. The synthesis routes of TPy, TPPy, TTPy, MeOTTPy, TPE-TTPy. Condition A: 1) Piperidine, EtOH, $78{ }^{\circ} \mathrm{C}$, overnight; 2) Acetone, $\mathrm{KPF}_{6}$, r.t., 2 h. Condition $\mathrm{B}: \mathrm{Pd}(\mathrm{dppf}) \mathrm{Cl}_{2}, \mathrm{~K}_{2} \mathrm{CO}_{3}, \mathrm{MeOH}$, Toluene, $75{ }^{\circ} \mathrm{C}, 16 \mathrm{~h}$.

Synthesis of TPy: A solution of 4-(diphenylamino)benzaldehyde (54.6 mg, $0.2 \mathrm{mmol}$ ) and 1,4-dimethylpyridin-1-ium iodide $(56.4 \mathrm{mg}, 0.24 \mathrm{mmol})$ was refluxed under nitrogen in dry ethanol catalyzed by a few drops of piperidine overnight. After cooling to room temperature, the mixture was poured into diethyl ether. The orange precipitates formed were filtered by suction filtration. The precipitates were re-dissolved in acetone and mixed with saturated $\mathrm{KPF}_{6}$ solution $(3 \mathrm{~mL})$. After stirring for $1 \mathrm{~h}$, acetone was evaporated by compressed air. The orange precipitates were filtered again, washed with water and dried under reduced pressure. The residue was purified by a neutral aluminum oxide column using DCM and methanol mixture $(99: 1 \mathrm{v} / \mathrm{v})$ as eluting solvent to give orange powder of TPy $\left(87 \mathrm{mg}, 86 \%\right.$ of yield). ${ }^{1} \mathrm{H}$ $\operatorname{NMR}\left(400 \mathrm{MHz}, \mathrm{DMSO}_{-}\right) \delta 8.78(\mathrm{~d}, J=6.6 \mathrm{~Hz}, 2 \mathrm{H}), 8.13(\mathrm{~d}, J=6.6 \mathrm{~Hz}, 2 \mathrm{H}), 7.94(\mathrm{~d}, J=16.2 \mathrm{~Hz}, 1 \mathrm{H})$, $7.64-7.59(\mathrm{~m}, 2 \mathrm{H}), 7.38(\mathrm{t}, J=7.8 \mathrm{~Hz}, 4 \mathrm{H}), 7.29(\mathrm{~d}, J=16.3 \mathrm{~Hz}, 1 \mathrm{H}), 7.17(\mathrm{~d}, J=7.3 \mathrm{~Hz}, 2 \mathrm{H}), 7.14-7.09$ $(\mathrm{m}, 4 \mathrm{H}), 6.95(\mathrm{~d}, J=8.6 \mathrm{~Hz}, 2 \mathrm{H}), 4.21(\mathrm{~s}, 3 \mathrm{H}) .{ }^{13} \mathrm{C}$ NMR $\left(100 \mathrm{MHz}, \mathrm{DMSO}-d_{6}\right) \delta 152.85,149.49,146.24$, 144.83, 140.54, 129.89, 129.70, 128.02, 125.44, 124.54, 122.95, 120.75, 120.51, 46.70. ESI HRMS: calcd. for $\mathrm{C}_{26} \mathrm{H}_{23} \mathrm{~N}_{2}\left[\mathrm{M}-\mathrm{PF}_{6}\right]^{+}:$363.1856, found: 363.1822 .

Synthesis of TPPy: The intermediate compound $\mathbf{1}$ was synthesized according to the literature method ${ }^{1}$. 
The following synthetic process was similar to TPy except for the change of starting materials. Pure TPPy was isolated as red powder with the yield of $78 \% .{ }^{1} \mathrm{H}$ NMR $\left(400 \mathrm{MHz}, \mathrm{DMSO}-d_{6}\right) \delta 8.85(\mathrm{~d}, J=6.4 \mathrm{~Hz}, 2 \mathrm{H})$, $8.21(\mathrm{~d}, J=6.4 \mathrm{~Hz}, 2 \mathrm{H}), 8.03(\mathrm{~d}, J=16.3 \mathrm{~Hz}, 1 \mathrm{H}), 7.85-7.76(\mathrm{~m}, 4 \mathrm{H}), 7.72-7.67(\mathrm{~m}, 2 \mathrm{H}), 7.54(\mathrm{~d}, J=$ $16.3 \mathrm{~Hz}, 1 \mathrm{H}), 7.36-7.30(\mathrm{~m}, 4 \mathrm{H}), 7.11-7.03(\mathrm{~m}, 8 \mathrm{H}), 4.25(\mathrm{~s}, 3 \mathrm{H}) \cdot{ }^{13} \mathrm{C}$ NMR $\left(100 \mathrm{MHz}, \mathrm{DMSO}-d_{6}\right) \delta$ $147.34,146.85$, 145.06, 140.21, 133.65, 132.51, 129.66, 128.80, 127.66, 126.57, 124.42, 123.53, 123.43, 122.87, 122.81, 46.87. ESI HRMS: calcd. for $\mathrm{C}_{32} \mathrm{H}_{27} \mathrm{~N}_{2}\left[\mathrm{M}-\mathrm{PF}_{6}\right]^{+}:$439.2169, found: 439.2167.

Synthesis of TTPy: TTPy was synthesized according to the literature method ${ }^{4}$.

Synthesis of MeOTTPy: The synthetic process was similar to TTPy except for the change of starting materials. Pure MeOTTPy was isolated as red powder with the yield of $84 \%$. ${ }^{1} \mathrm{H}$ NMR (400 $\mathrm{MHz}$, DMSO- $\left.d_{6}\right): 8.76(\mathrm{~d}, J=6.8 \mathrm{~Hz}, 2 \mathrm{H}), 8.12-8.19(\mathrm{~m}, 3 \mathrm{H}), 7.53(\mathrm{~d}, J=8.8 \mathrm{~Hz}, 2 \mathrm{H}), 7.43-7.47(\mathrm{~m}, 2 \mathrm{H})$, 7.06-7.10 (m, 5H), 6.94-6.96 (m, 4H), $6.77(\mathrm{~d}, J=8.8 \mathrm{~Hz}, 2 \mathrm{H}), 4.2(\mathrm{~s}, 3 \mathrm{H}), 3.76(\mathrm{~s}, 6 \mathrm{H}) .{ }^{13} \mathrm{C}$ NMR $(100$ MHz, DMSO- $\left.d_{6}\right): 156.24,152.23,148.96,147.80$, 144.70, 139.26, 138.00, 133.86, 133.83, 127.26, 126.63, 123.98, 123.39, 122.79, 120.75, 118.41, 115.07, 55.25, 46.66. ESI HRMS: calcd. for $\mathrm{C}_{32} \mathrm{H}_{29} \mathrm{~N}_{2} \mathrm{O}_{2} \mathrm{~S}[\mathrm{M}-\mathrm{PF}]^{+}$: 505.1950, found: 505.1931 .

Synthesis of compound 5: A mixture of compound 4 ( $1 \mathrm{mmol})$, (5-formylthiophen-2-yl)boronic acid (1.2 $\mathrm{mmol}), \mathrm{Pd}(\mathrm{dppf}) \mathrm{Cl}_{2}(36.6 \mathrm{mg}, 0.05 \mathrm{mmol}), \mathrm{K}_{2} \mathrm{CO}_{3}(0.69 \mathrm{~g}), \mathrm{MeOH}(10 \mathrm{~mL})$ and Toluene $(10 \mathrm{~mL})$ was degassed and charged with $\mathrm{N}_{2}$. The mixture was refluxed for $16 \mathrm{~h}$. The reaction was quenched by the addition of water $(30 \mathrm{~mL})$ and extracted with $\mathrm{CH}_{2} \mathrm{Cl}_{2}(3 \times 30 \mathrm{~mL})$. The combined organic layer was dried over anhydrous $\mathrm{Na}_{2} \mathrm{SO}_{4}$ and evaporated. The residue was purified by column chromatography over silica gel to afford the desired product 5 with the yield of $82 \%$. ${ }^{1} \mathrm{H}$ NMR $\left(400 \mathrm{MHz}, \mathrm{CD}_{2} \mathrm{Cl}_{2}\right): 9.84(\mathrm{~s}, 1 \mathrm{H}), 7.72$ (d, J $=4 \mathrm{~Hz}, 1 \mathrm{H}), 7.54(\mathrm{~d}, \mathrm{~J}=8.8 \mathrm{~Hz}, 2 \mathrm{H}), 7.28-7.34(\mathrm{~m}, 3 \mathrm{H}), 7.00-7.18(\mathrm{~m}, 20 \mathrm{H}), 6.95(\mathrm{~d}, \mathrm{~J}=8.4 \mathrm{~Hz}, 2 \mathrm{H}), 6.85$ $(\mathrm{d}, \mathrm{J}=8.4 \mathrm{~Hz}, 2 \mathrm{H}) .{ }^{13} \mathrm{C}$ NMR $\left(100 \mathrm{MHz}, \mathrm{CD}_{2} \mathrm{Cl}_{2}\right): 183.05,154.65,149.44$, 147.33, 145.73, 144.47, 144.27, 144.05 , 141.97, 141.53, 141.11, 139.87, 138.35, 132.82, 131.82, 131.78, 131.75, 129.96, 128.21, 128.18, 128.15, 127.68, 127.02, 126.97, 126.92, 126.69, 125.68, 124.52, 124.42, 123.55, 122.91. ESI HRMS: calcd. for $\mathrm{C}_{43} \mathrm{H}_{31} \mathrm{NOS}[\mathrm{M}]^{+}$: 609.2126, found: 609.2106.

Synthesis of TPE-TTPy: Solution of compound $5(121.8 \mathrm{mg}, 0.2 \mathrm{mmol})$ and 1,4-dimethylpyridin-1-ium iodide $(56.4 \mathrm{mg}, 0.24 \mathrm{mmol})$ was refluxed under nitrogen in dry ethanol catalyzed by a few drops of piperidine overnight. After cooling to room temperature, the mixture was poured into diethyl ether. The red precipitates formed were filtered by suction filtration. The precipitates were re-dissolved in acetone and mixed with saturated $\mathrm{KPF}_{6}$ solution $(3 \mathrm{~mL})$. After stirring for $1 \mathrm{~h}$, acetone was evaporated by compressed air. The red precipitates were filtered again, washed with water and dried under reduced pressure. The residue was purified by a neutral aluminum oxide column using DCM and methanol mixture (99:1 v/v) as eluting 
solvent to give red powder of TPE-TTPy $\left(128 \mathrm{mg}, 76 \%\right.$ of yield). ${ }^{1} \mathrm{H}$ NMR $\left(400 \mathrm{MHz}, \mathrm{DMSO}-d_{6}\right) \delta 8.75$ (d, $J=6.5 \mathrm{~Hz}, 2 \mathrm{H}), 8.20-8.11(\mathrm{~m}, 3 \mathrm{H}), 7.65-7.57(\mathrm{~m}, 2 \mathrm{H}), 7.50(\mathrm{q}, J=3.9 \mathrm{~Hz}, 2 \mathrm{H}), 7.35-7.30(\mathrm{~m}, 2 \mathrm{H})$, $7.19-7.10(\mathrm{~m}, 10 \mathrm{H}), 7.04-6.95(\mathrm{~m}, 9 \mathrm{H}), 6.93-6.89(\mathrm{~m}, 4 \mathrm{H}), 6.82-6.78(\mathrm{~m}, 2 \mathrm{H}), 4.20(\mathrm{~s}, 3 \mathrm{H}) .{ }^{13} \mathrm{C}$ NMR (100 MHz, DMSO- $\left.d_{6}\right) \delta 152.32,147.27,146.41,144.91,144.88,143.39,143.18,142.95,140.72$, $138.80,133.86,132.07,130.85,130.77,129.84,128.02,127.95,127.86,126.90,126.75,126.68,124.72$, $124.39,124.05,123.84,123.05,122.49,121.32$, 46.86. ESI HRMS: calcd. for $\mathrm{C}_{50} \mathrm{H}_{39} \mathrm{~N}_{2} \mathrm{~S}\left[\mathrm{M}-\mathrm{PF}_{6}\right]^{+}:$699.2834, found: 699.2852 .

\section{NMR and HRMS spectra of AIEgens}




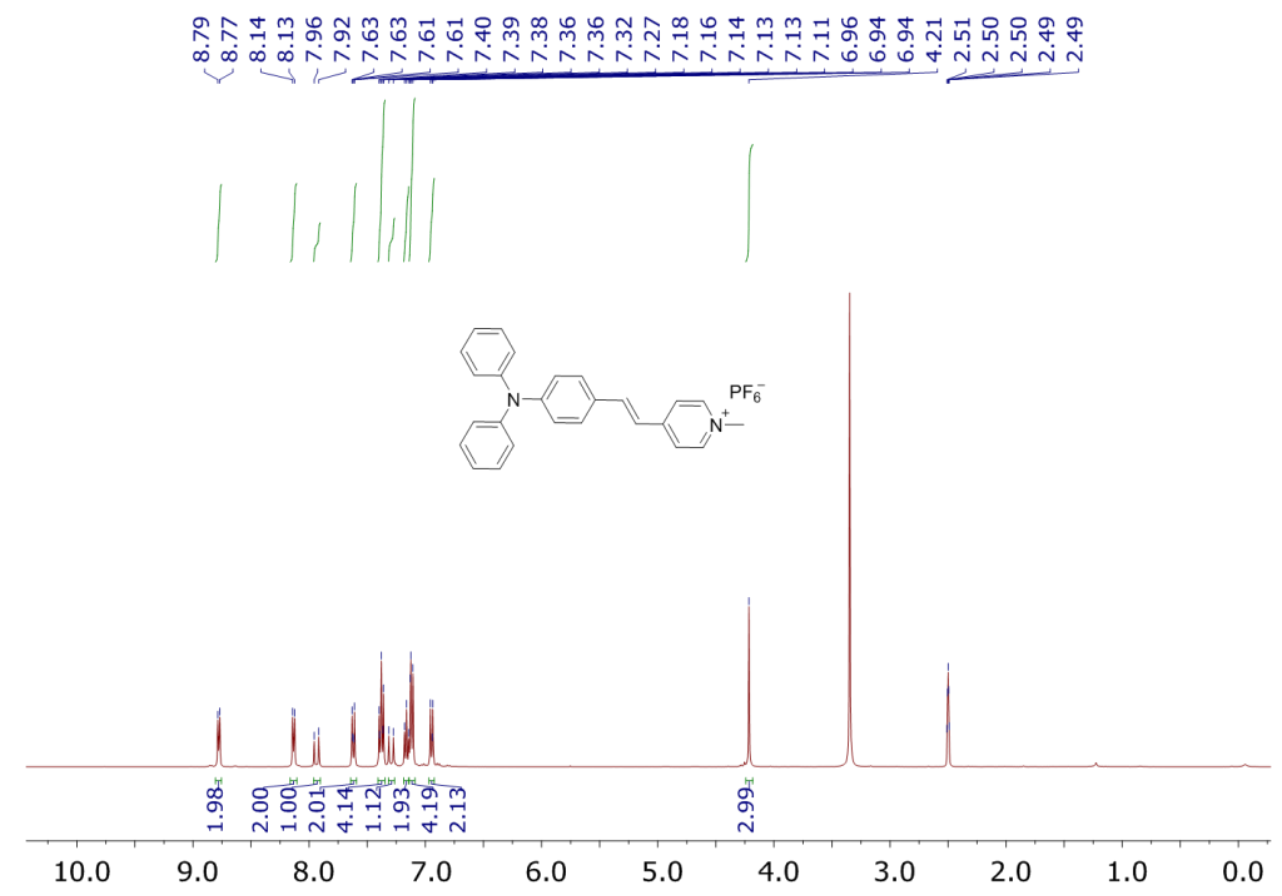

Figure S2. 1H NMR spectrum of TPy.

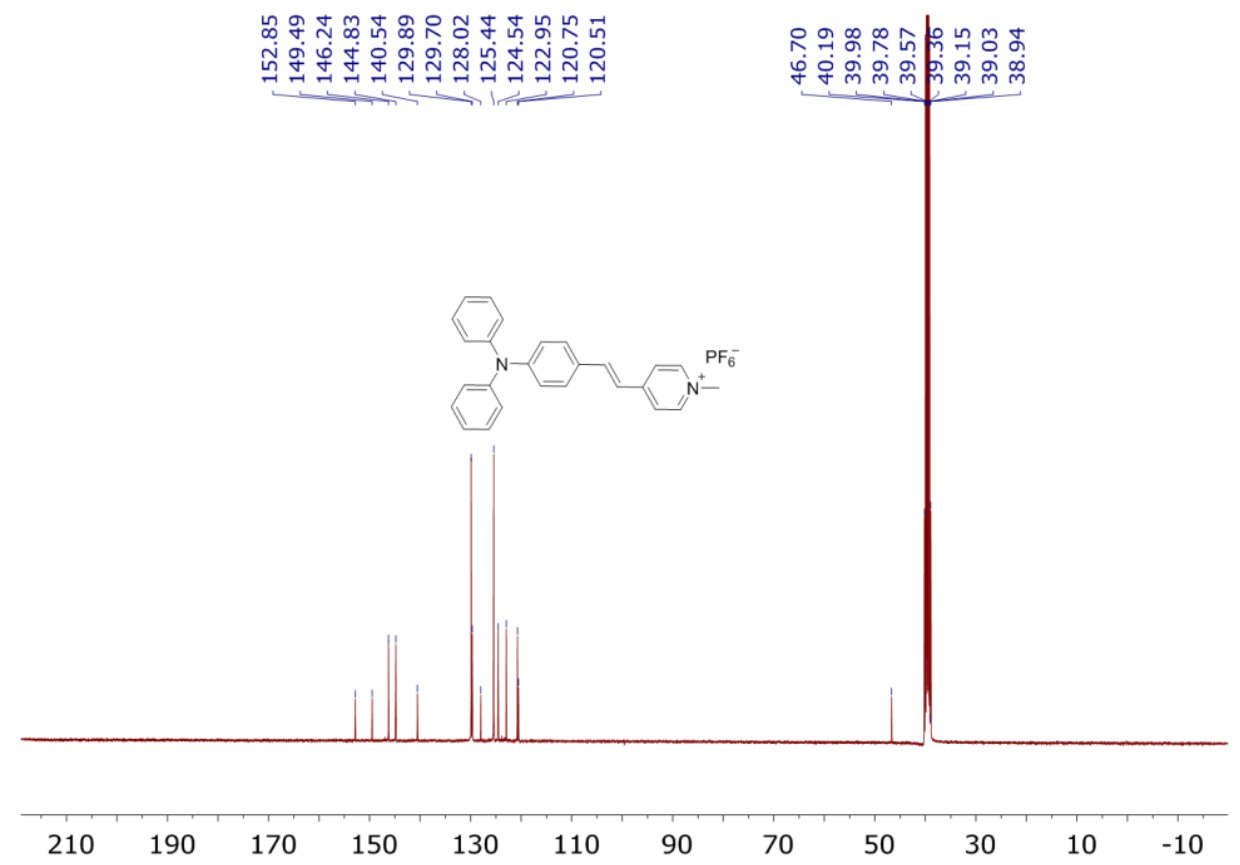

Figure S3. ${ }^{13} \mathrm{C}$ NMR spectrum of TPy. 


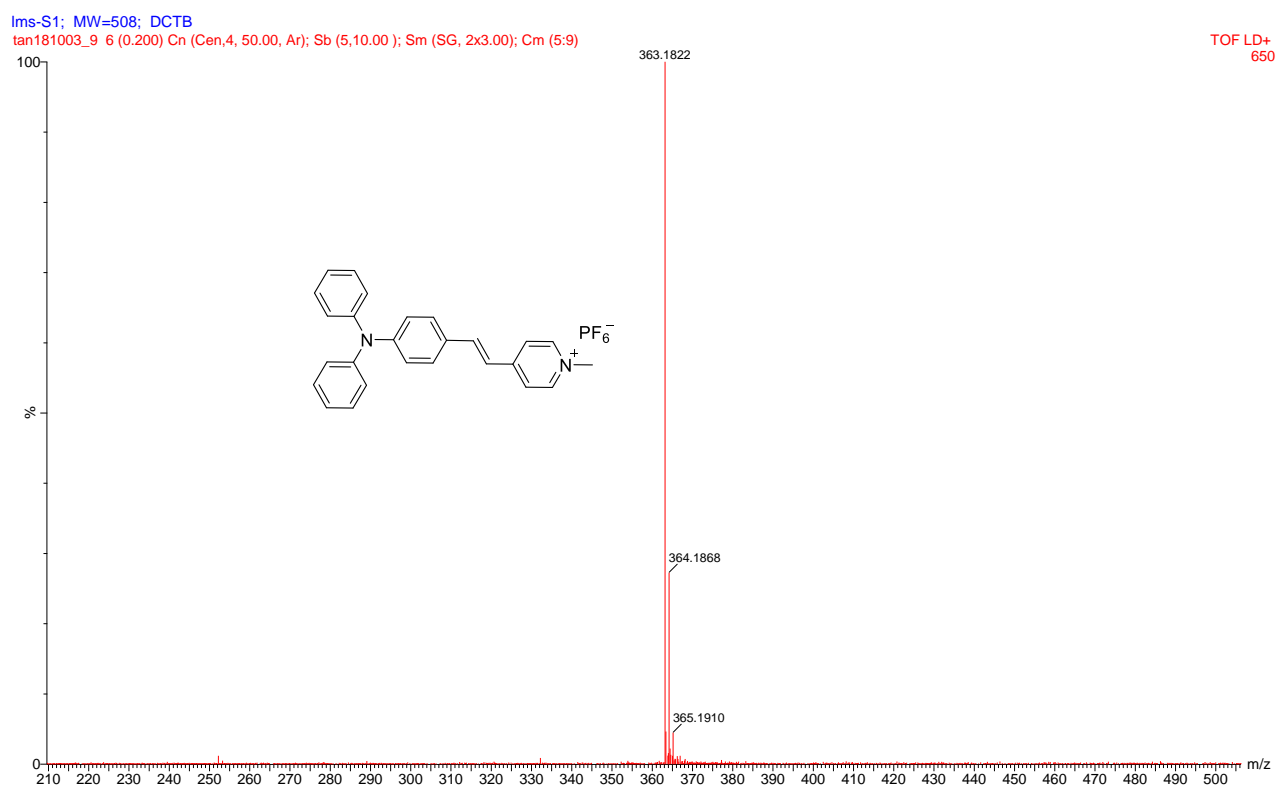

Figure S4. HRMS spectrum of TPy.

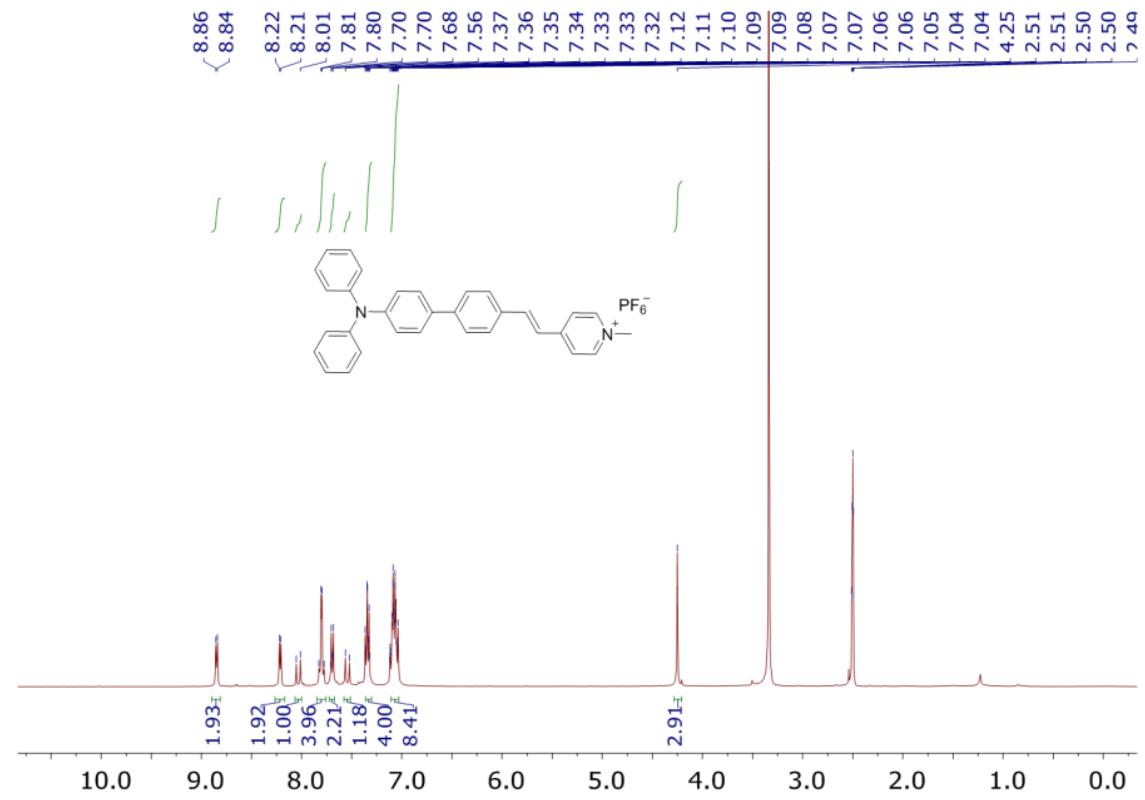

Figure S5. ${ }^{1} \mathrm{H}$ NMR spectrum of TPPy. 


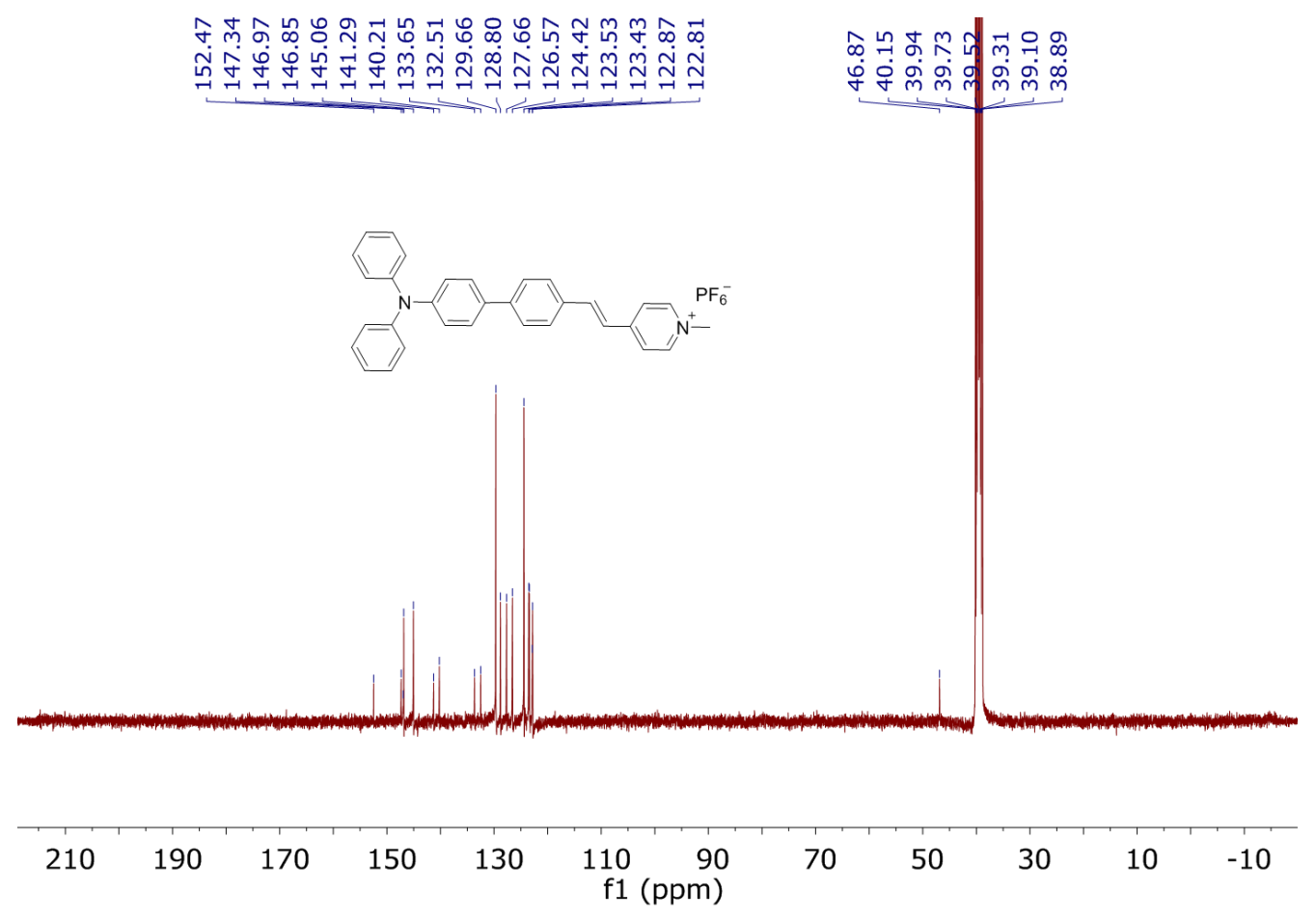

Figure S6. ${ }^{13} \mathrm{C}$ NMR spectrum of TPPy.

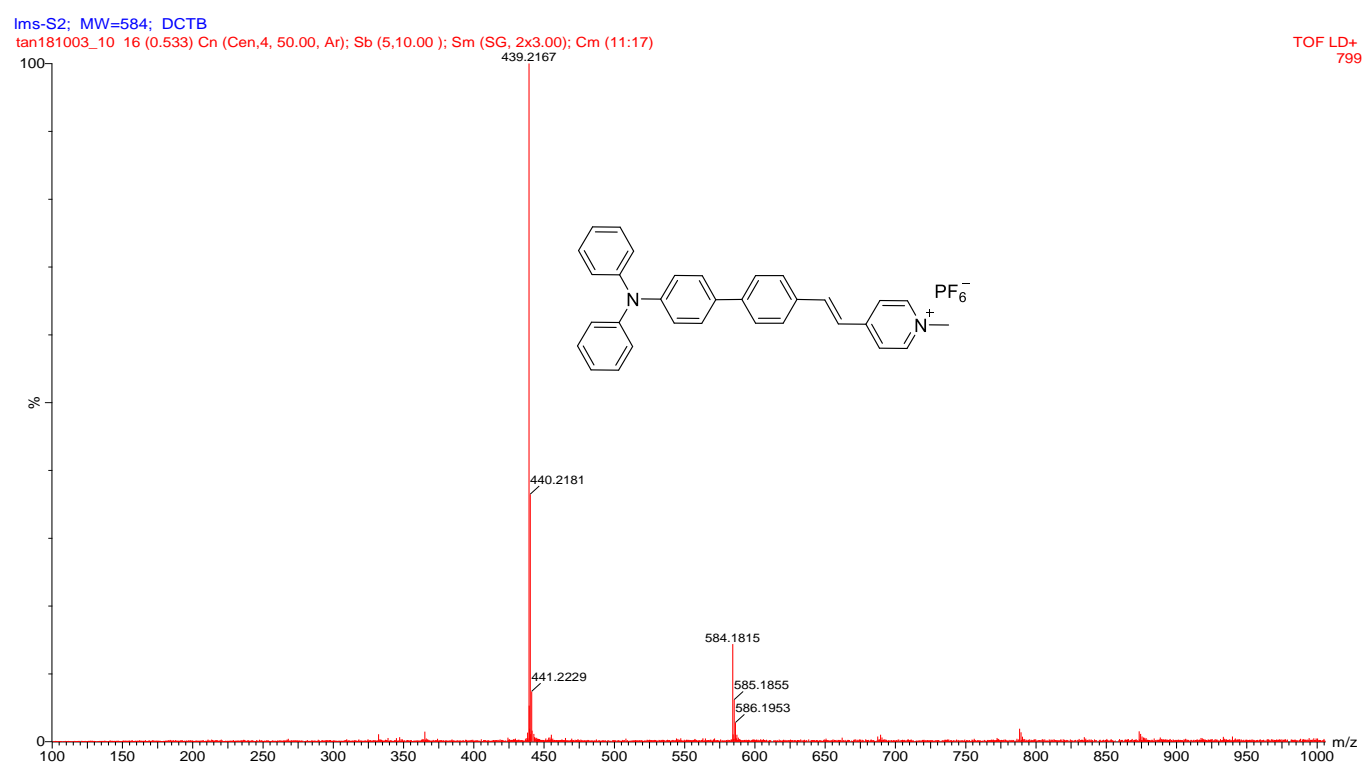

Figure S7. HRMS spectrum of TPPy. 


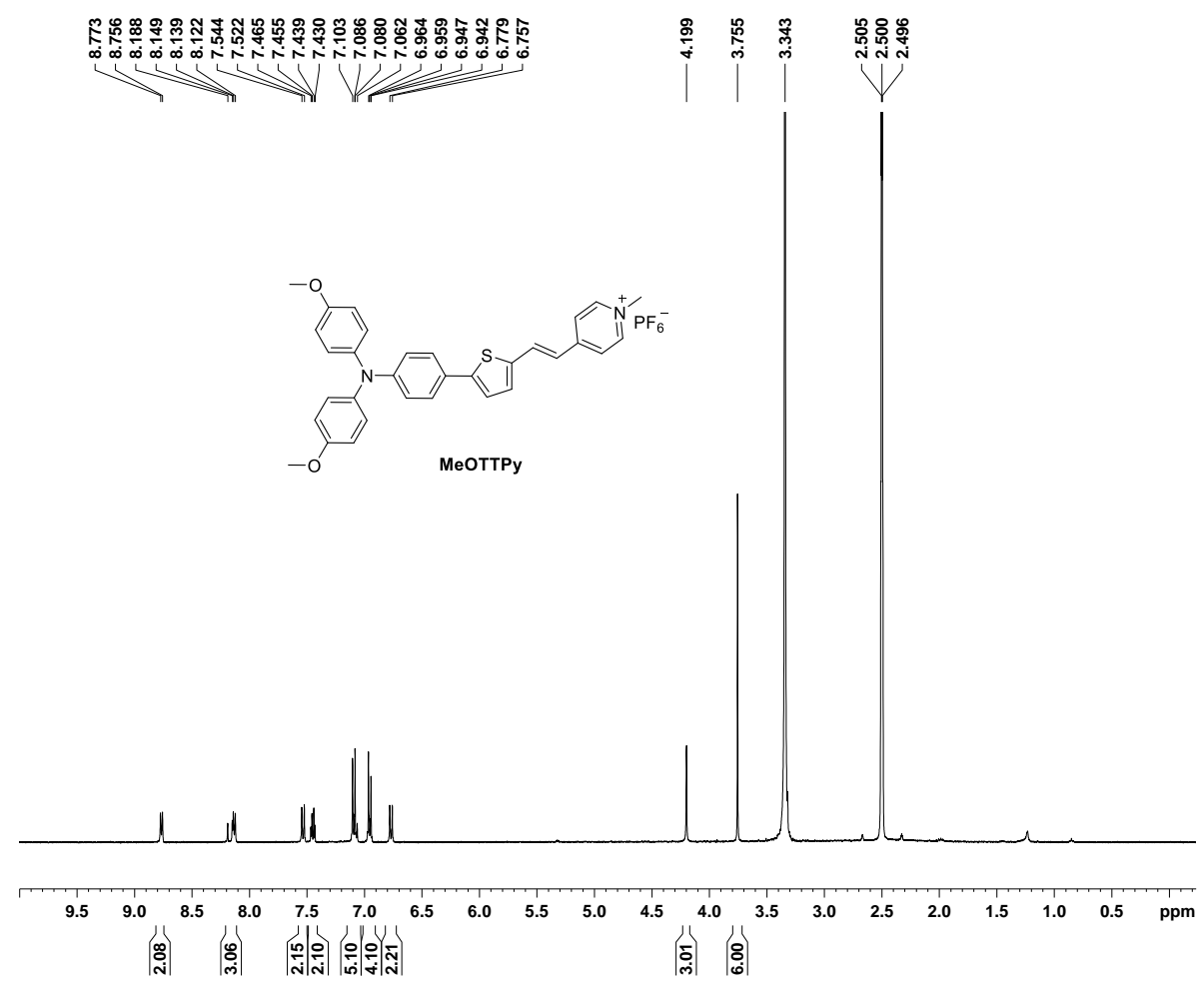

Figure S8. ${ }^{1} \mathrm{H}$ NMR spectrum of MeOTTPy.

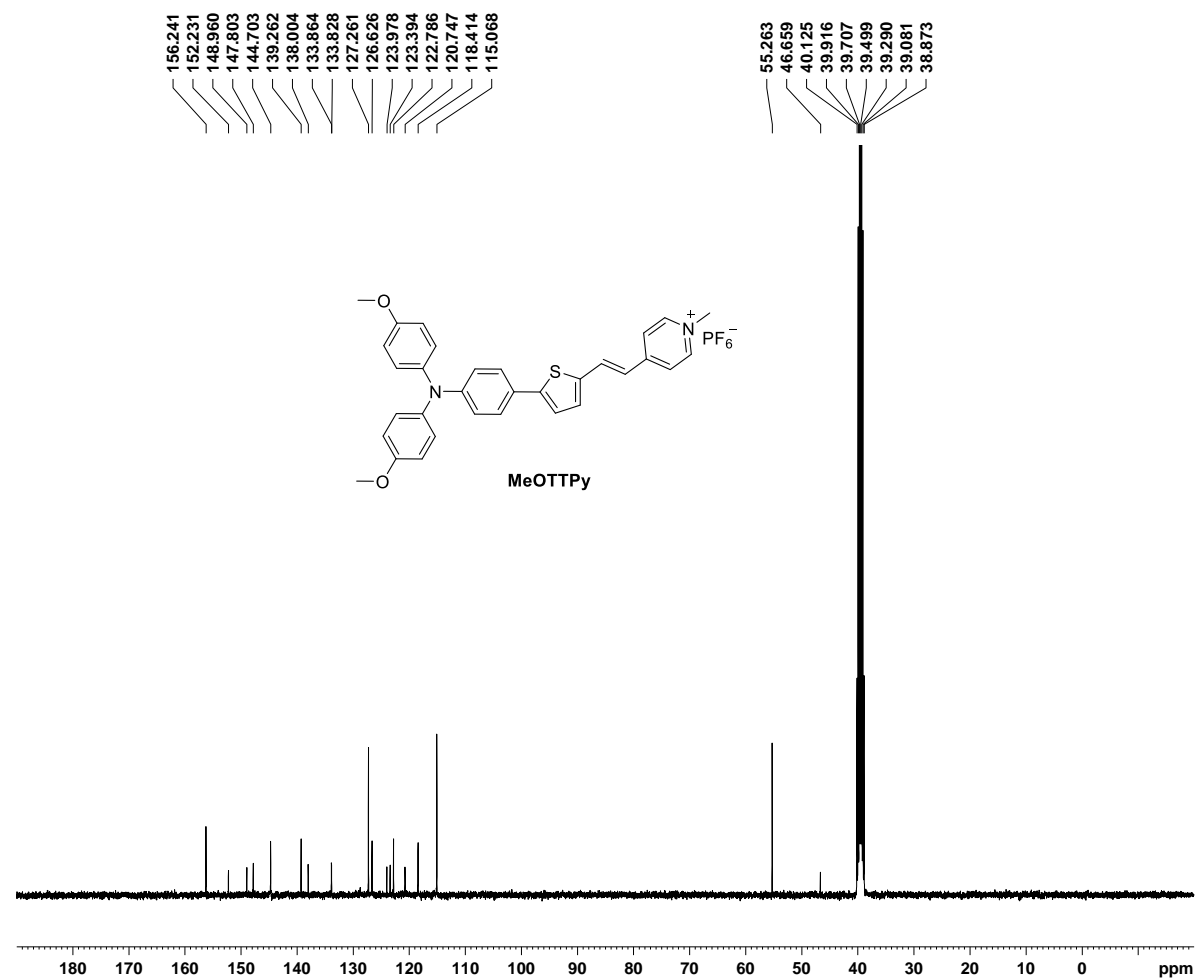

Figure S9. ${ }^{13} \mathrm{C}$ NMR spectrum of MeOTTPy. 


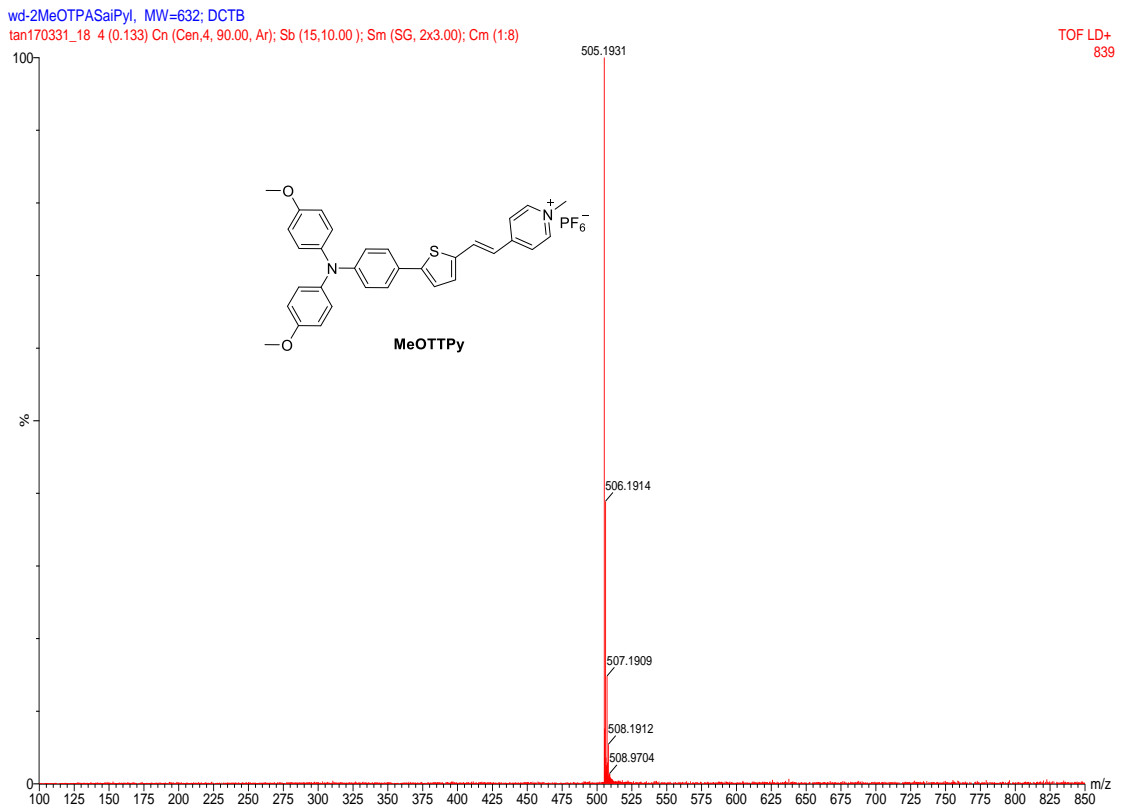

Figure S10. HRMS spectrum of MeOTTPy.

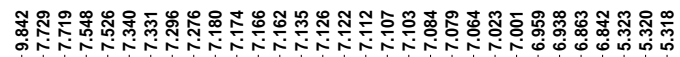
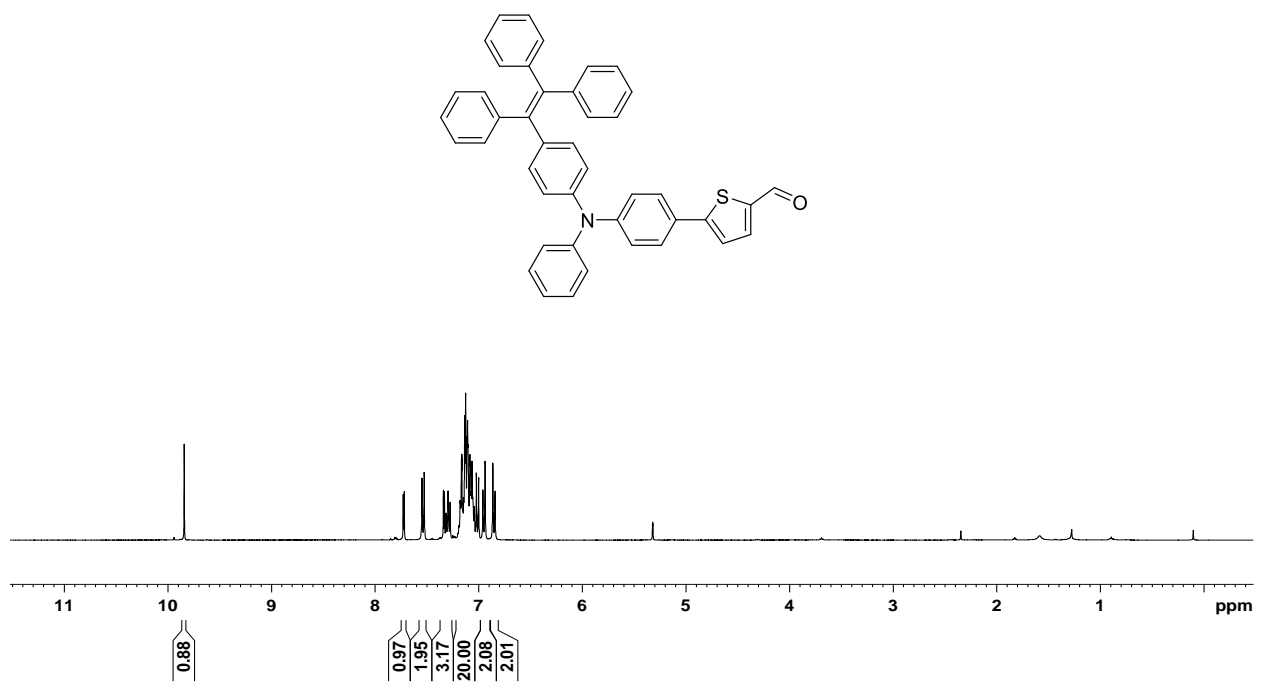

Figure S1 1. ${ }^{1} \mathrm{H}$ NMR spectrum of Compound 5. 


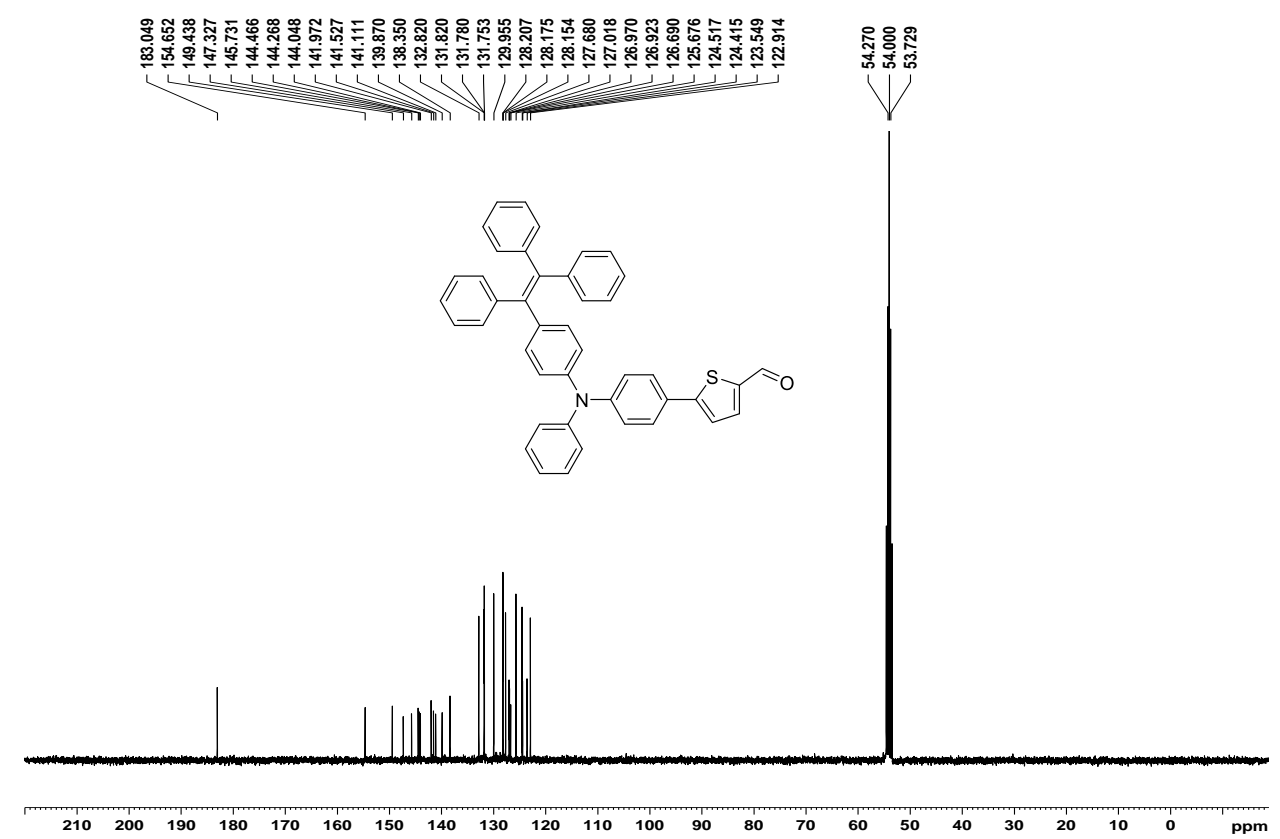

Figure S12. ${ }^{13} \mathrm{C}$ NMR spectrum of Compound 5.

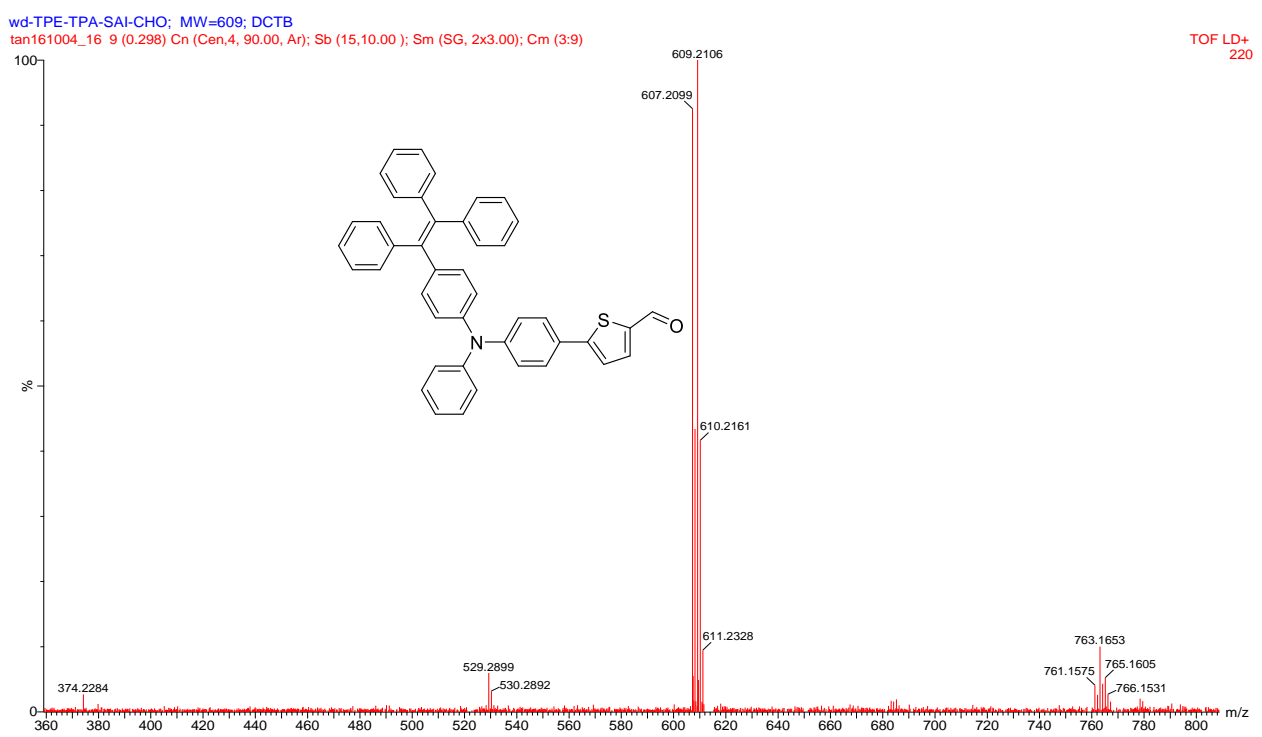

Figure S13. HRMS spectrum of Compound 5. 


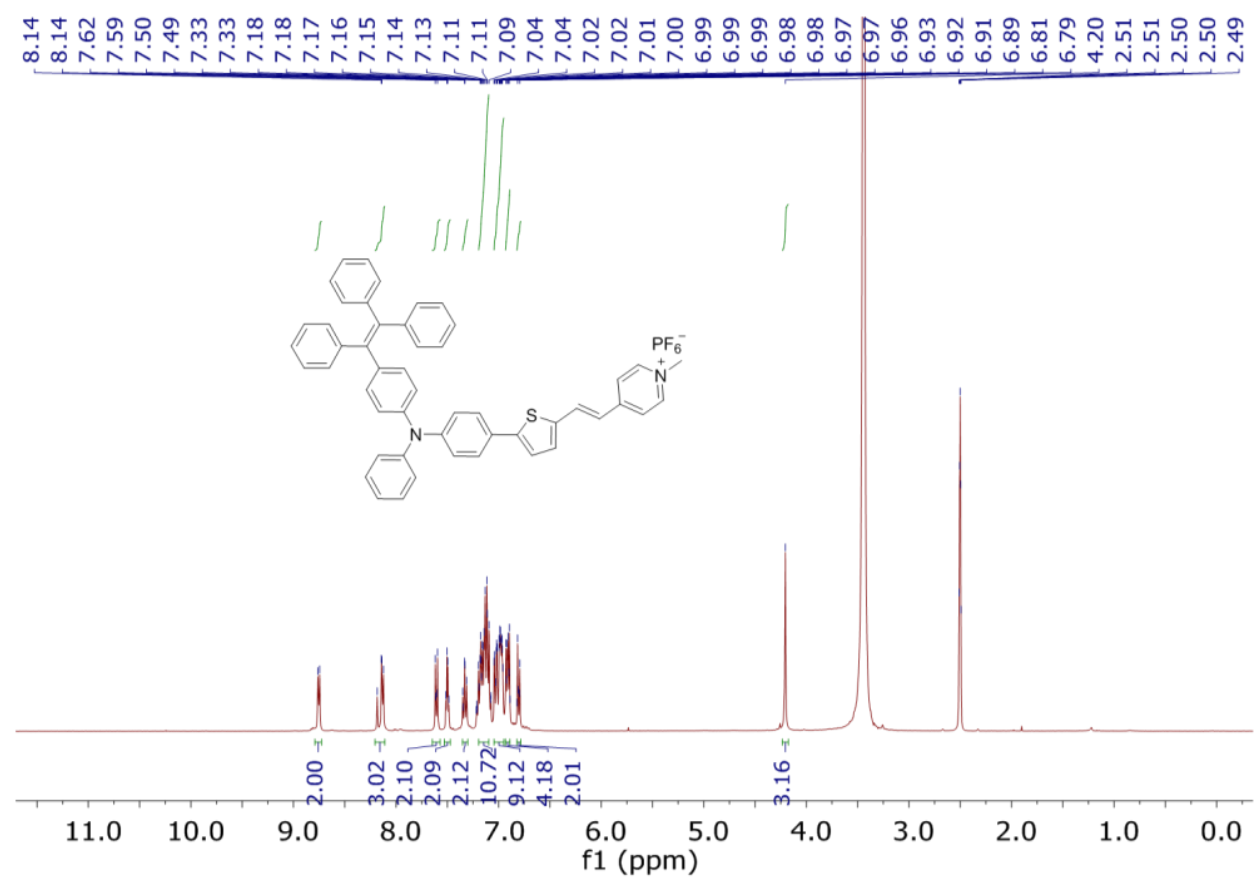

Figure S14. ${ }^{1} \mathrm{H}$ NMR spectrum of TPE-TTPy.

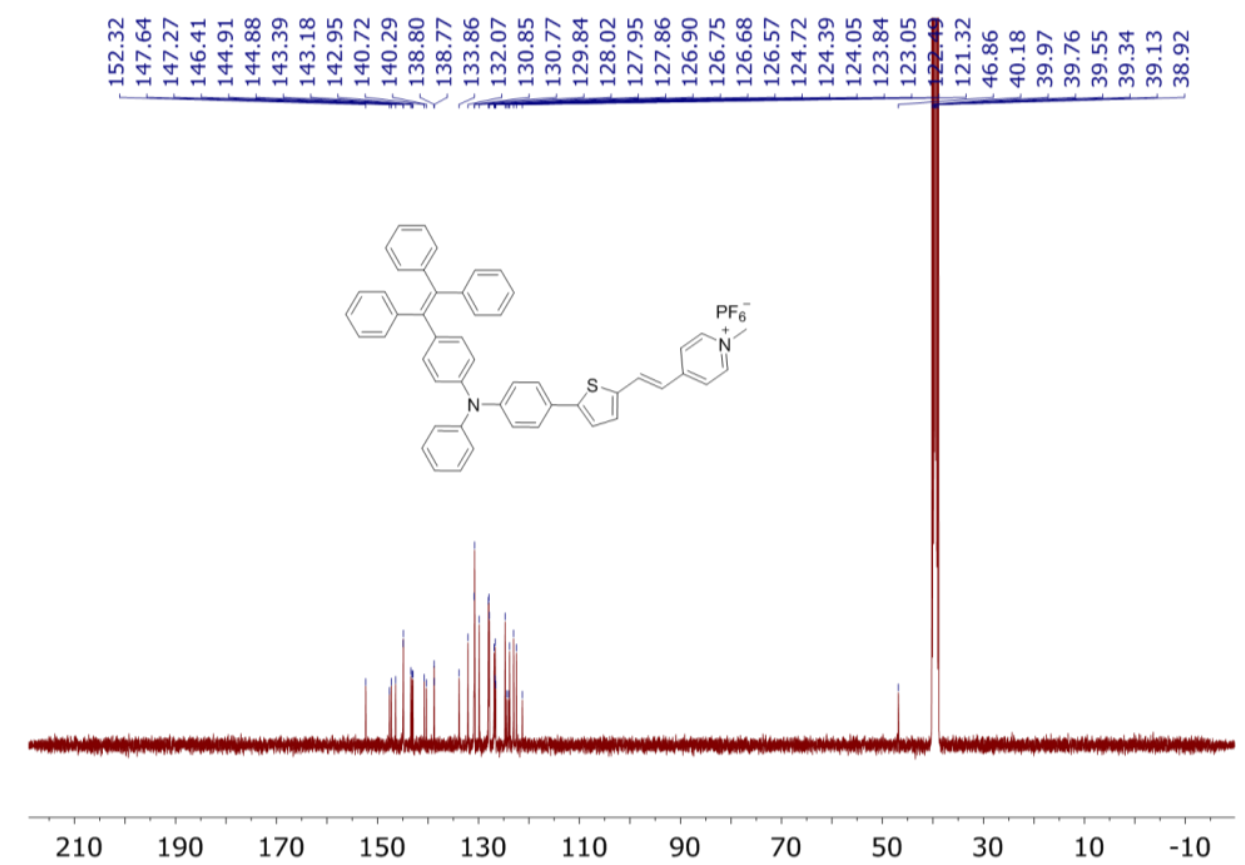

Figure S15. ${ }^{13} \mathrm{C}$ NMR spectrum of TPE-TTPy. 


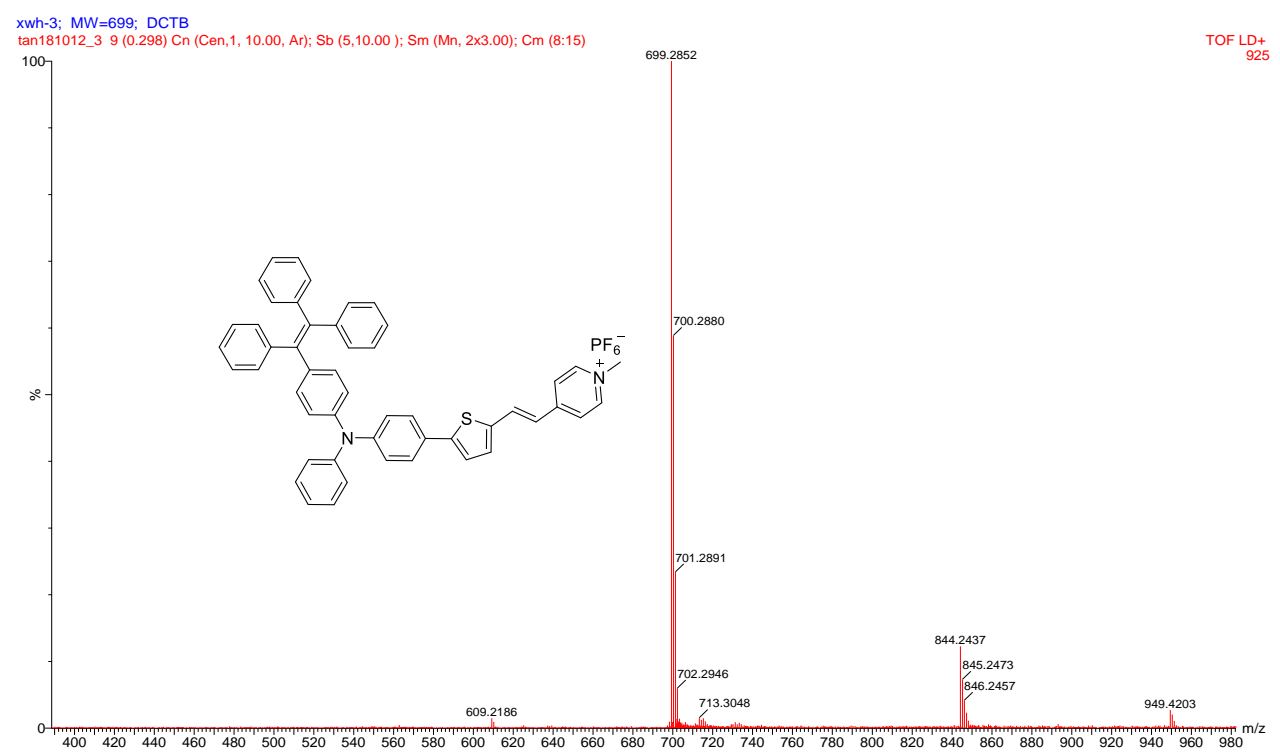

Figure S16. HRMS spectrum of TPE-TTPy.
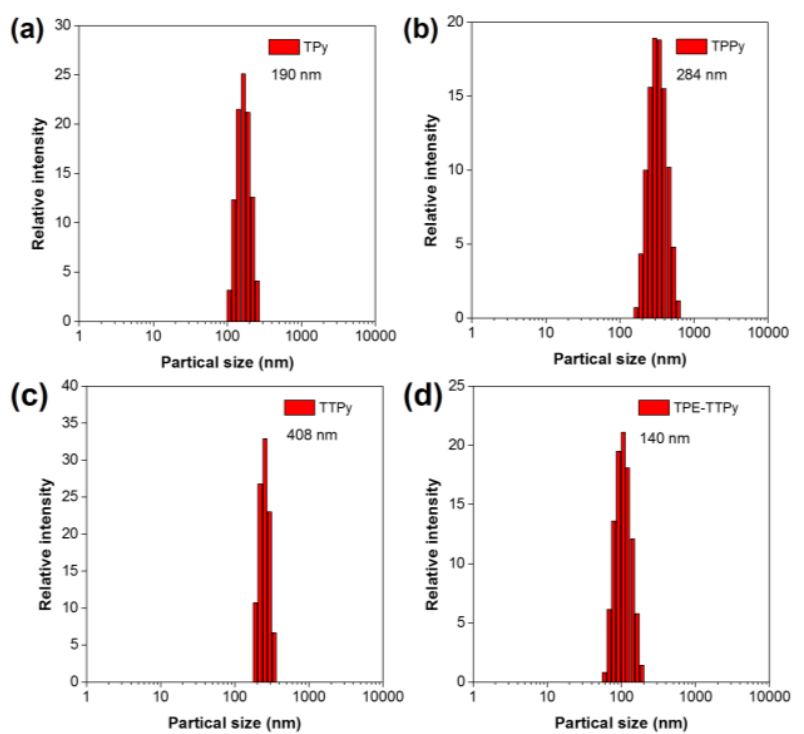

Figure S17. Size distribution of the aggregates of TPy (a), TPPy (b), TTPy (c) and TPE-TTPy (d) in DMSO/water mixtures with $95 \%$ water fraction at the concentration of $1 \times 10^{-5} \mathrm{M}$. 


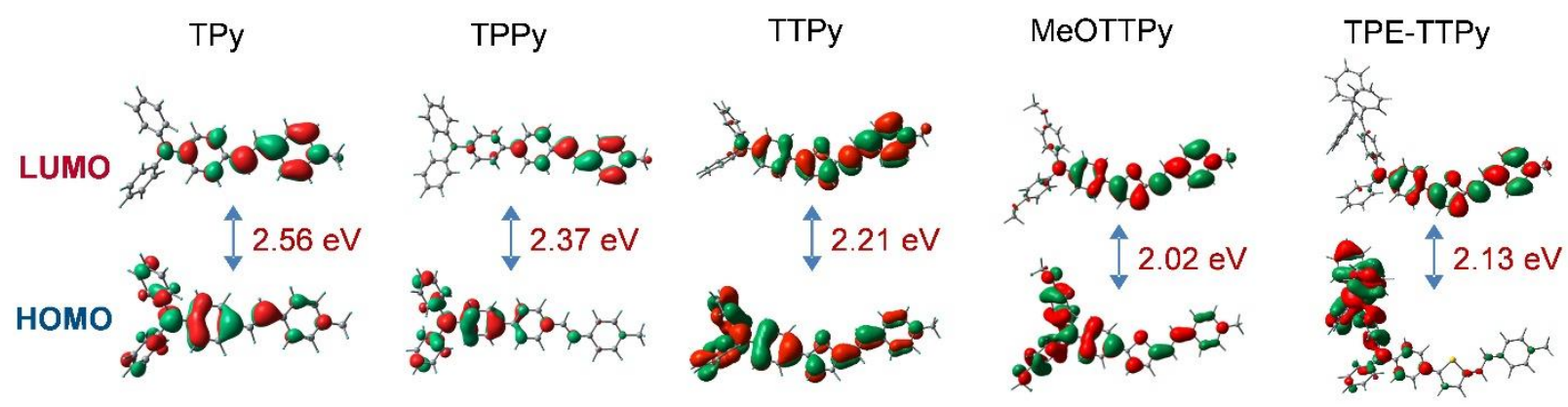

Figure S18. Frontier molecular orbitals for TPy, TPРy, ТTPy, MeOTTPy and TPE-TTPy. Calculations were performed by density functional theory calculations at the B3LYP/6-31G* level using the Gaussian 09 program.

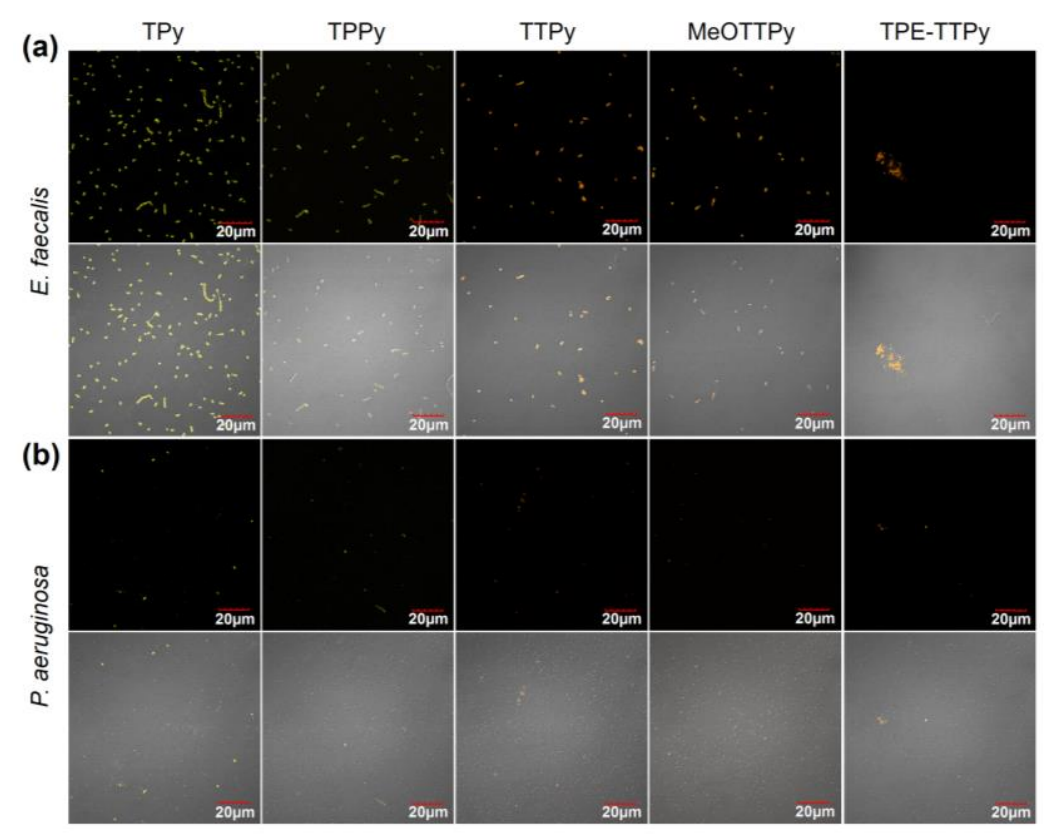

Figure S19. Bacteria staining and imaging of AIEgens. Confocal images of Gram-positive E. faecalis (a) and Gram-negative P. aeruginosa (b) incubated with TPy, TPPy, TTPy, MeOTTPy and TPE-TTPy at the concentration of $2 \times 10^{-6} \mathrm{M}$ for $20 \mathrm{~min}$. 


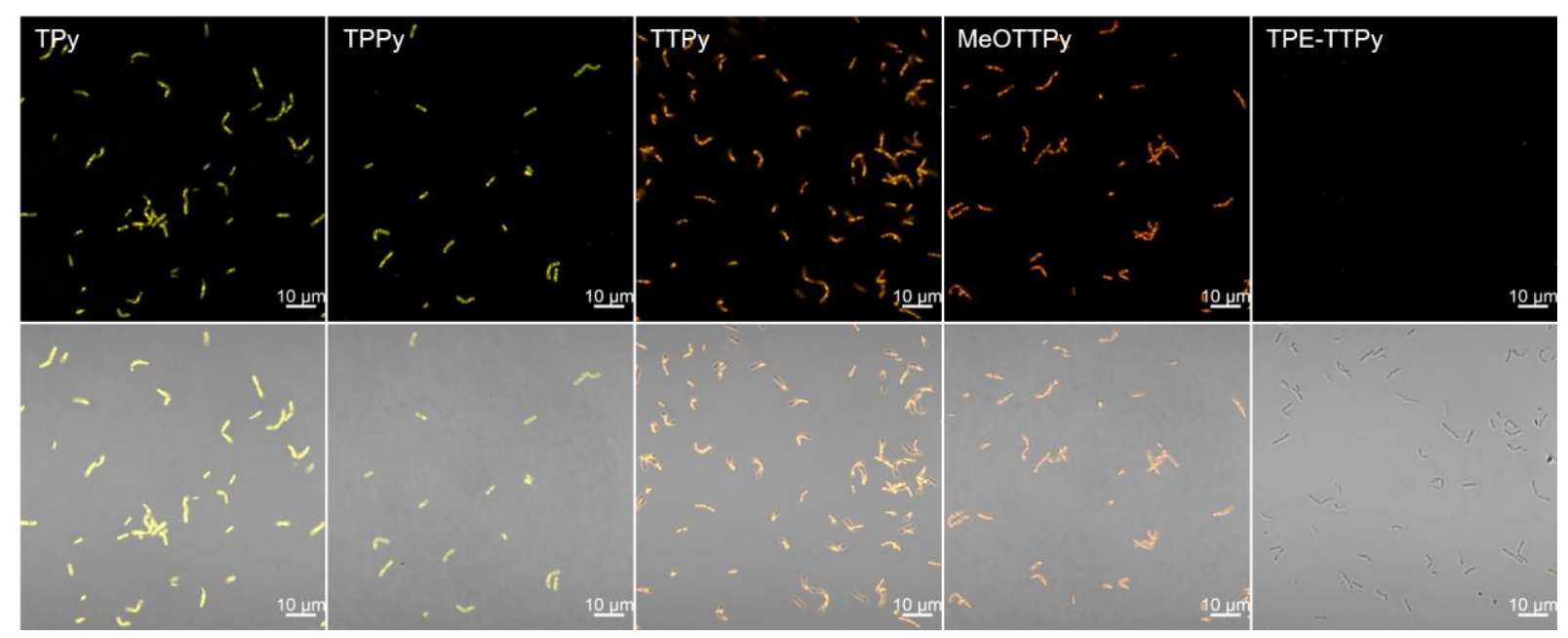

Figure S20. Bacteria staining and imaging of AIEgens. Confocal images of Gram-positive B. subtilis incubated with TPy, TPPy, TTPy, MeOTTPy and TPE-TTPy at the concentration of $2 \times 10^{-6} \mathrm{M}$ for 20 $\min$.

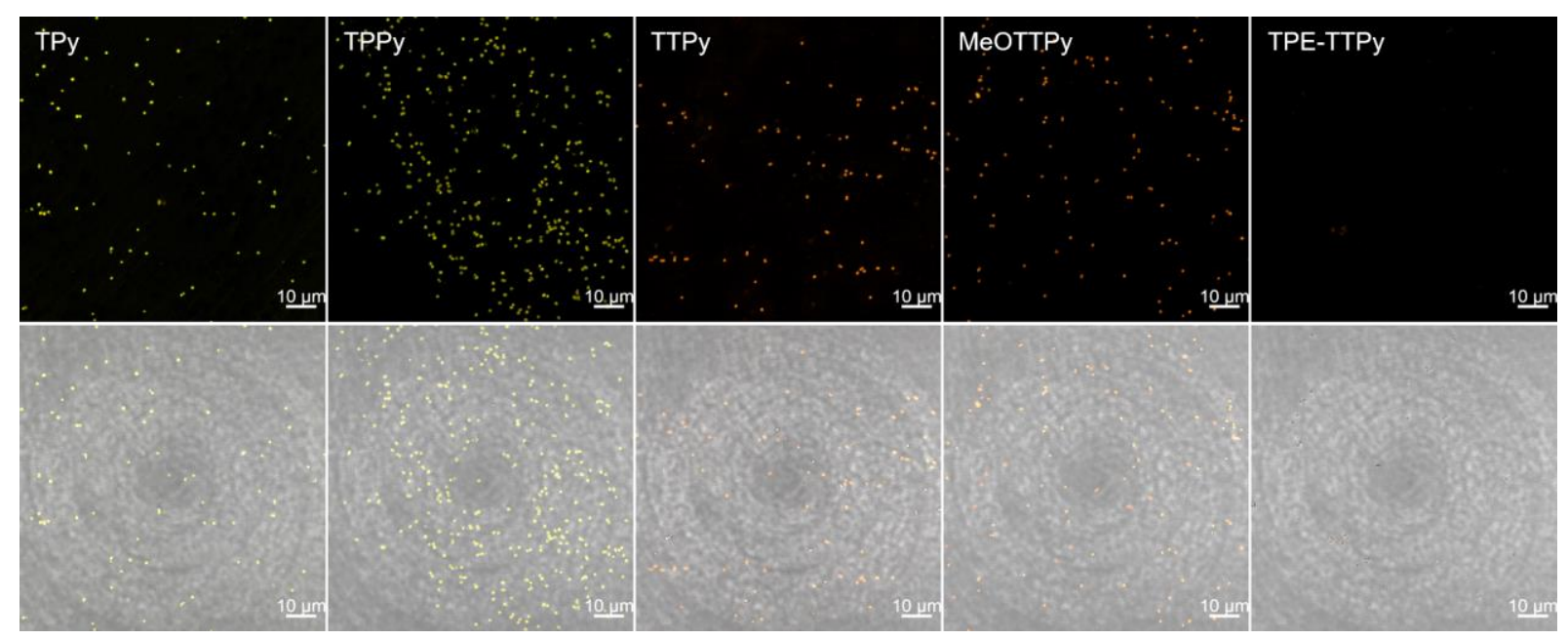

Figure S21. Bacteria staining and imaging of AIEgens. Confocal images of Gram-positive $S$. epidermidis incubated with TPy, TPPy, TTPy, MeOTTPy and TPE-TTPy at the concentration of $2 \times$ $10^{-6} \mathrm{M}$ for $20 \mathrm{~min}$. 


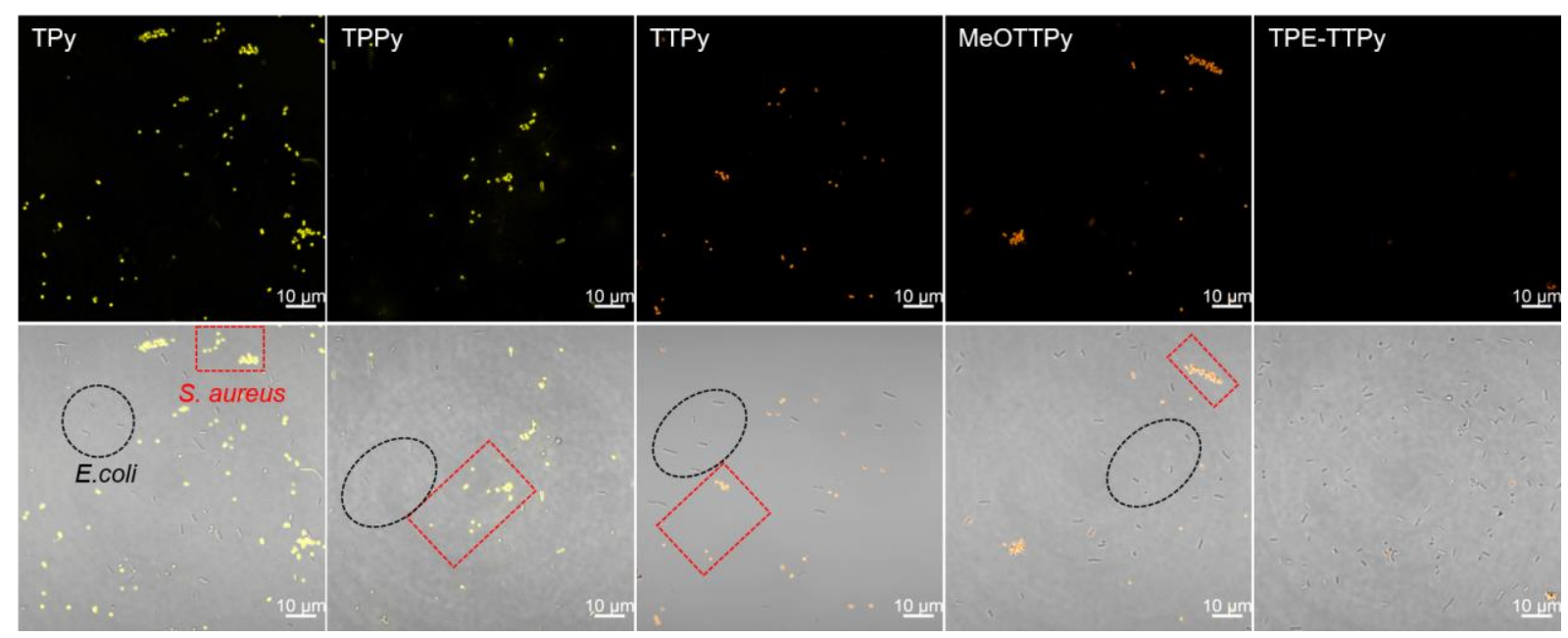

Figure S22. Selective Gram-positive bacteria imaging of AIEgens in bacteria mixtures. Confocal images of bacteria mixtures including Gram-positive S. aureus (globular-shaped) and Gram-negative E. coli (clavate-shaped) incubated with TPy, TPPy, TTPy, MeOTTPy and TPE-TTPy at the concentration of $2 \times 10^{-6} \mathrm{M}$ for $20 \mathrm{~min}$.

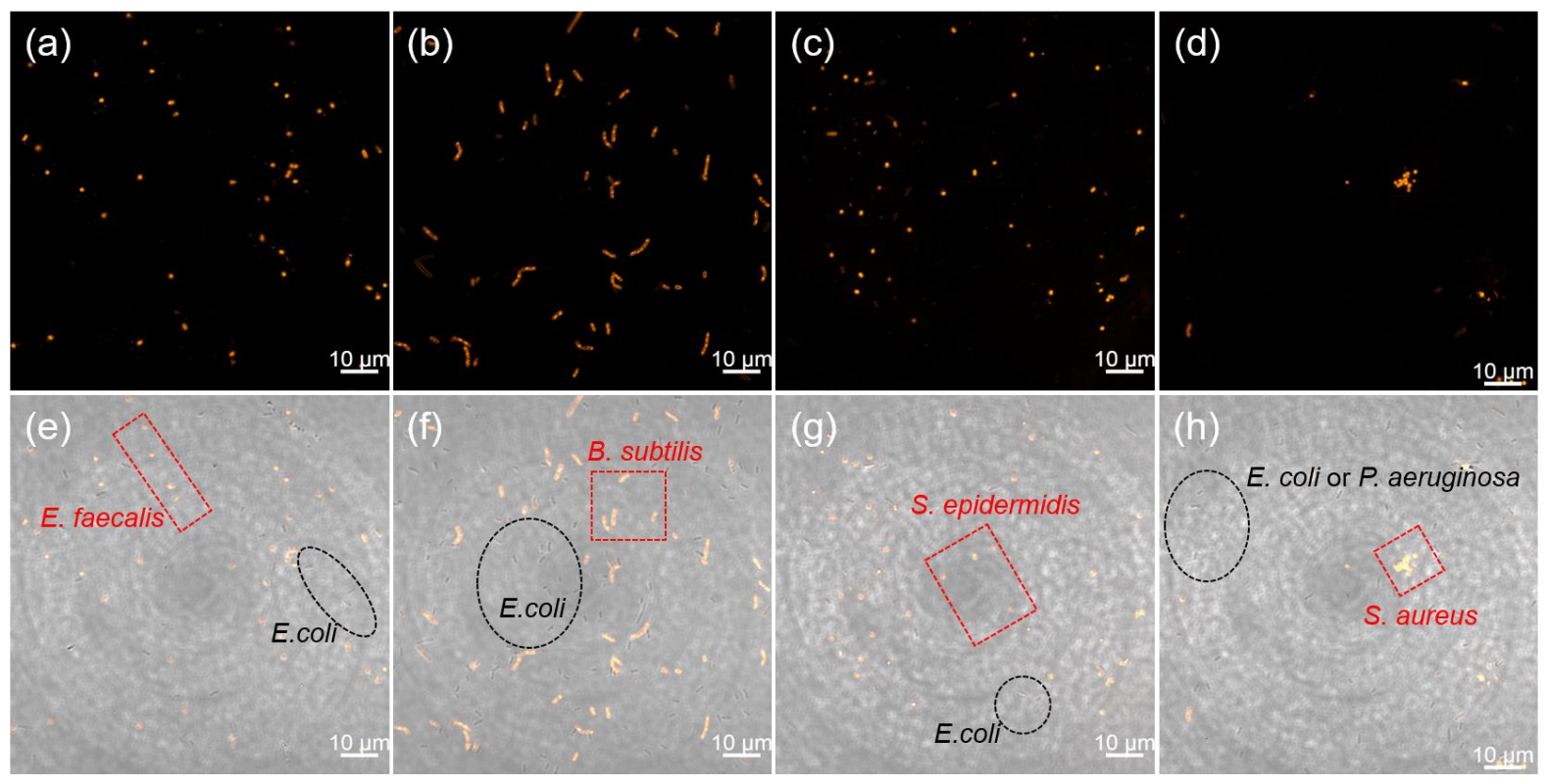

Figure S23. Selective Gram-positive bacteria imaging of TTPy in bacteria mixtures. Confocal images of bacteria mixtures including (a, e) E. faecalis and E. coli, (b, f) B. subtilis and E. coli, (c, g) S. epidermidis and E. coli, (d, h) S. aureus, E. coli and P. aeruginosa incubated with TPPy $\left(2 \times 10^{-6} \mathrm{M}\right)$ for $20 \mathrm{~min}$. 

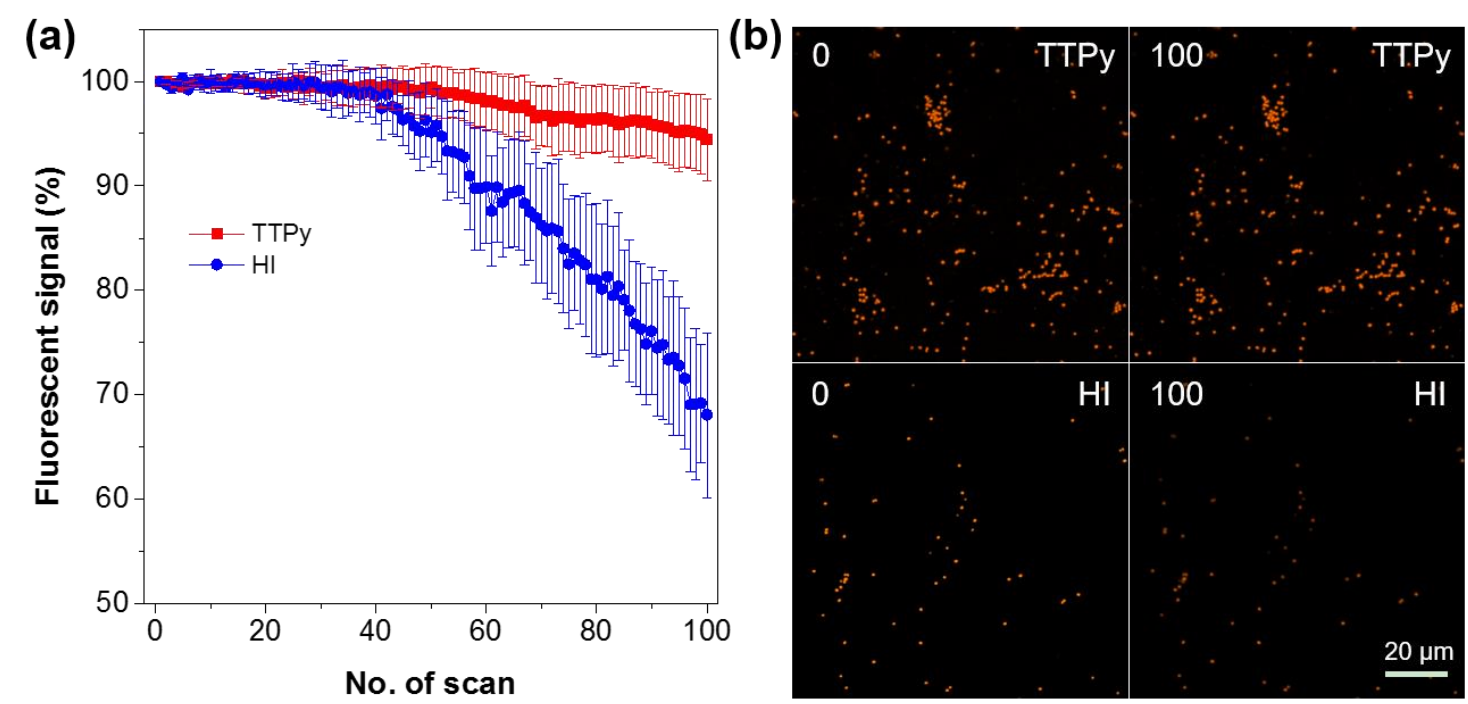

Figure S24. Photostability of TTPy and HI. (a) Loss in fluorescence of S. aureus stained with TTPy and HI with the number of scans of laser irradiation. (b) Confocal images of S. aureus stained with TTPy (upper panel) and HI (lower panel) before and after 100 scans of laser irradiation. Concentration: $2 \times 10^{-6} \mathrm{M}$; $\lambda_{\mathrm{ex}}: 488 \mathrm{~nm}$ (2\% laser intensity).
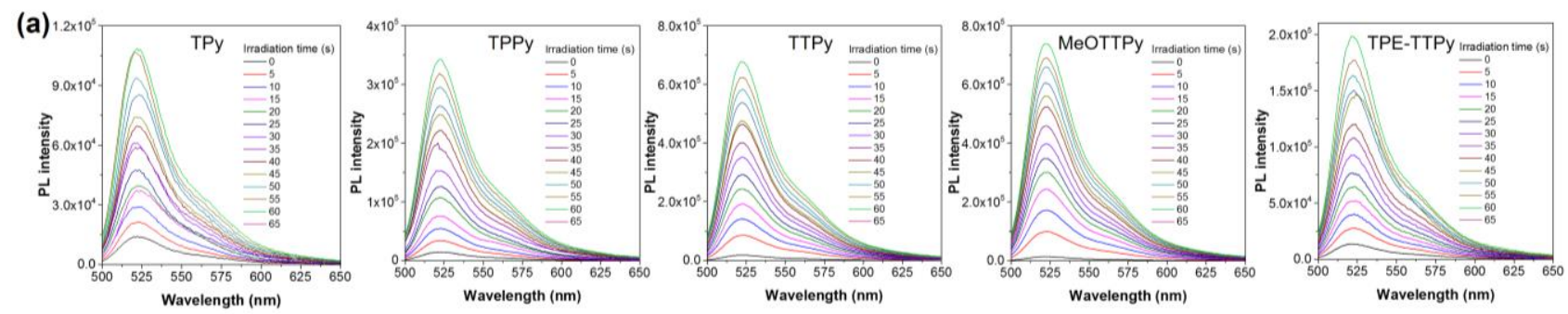

(b)
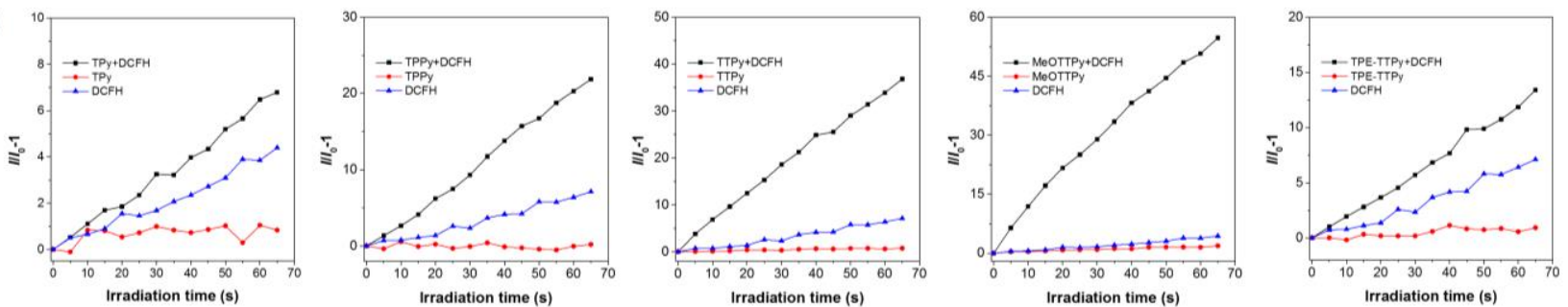

Figure S25. Light-induced ROS generation of AIEgens monitored by DCFH. (a) PL spectra of mixtures of DCFH and AIEgens $\left(5 \times 10^{-8} \mathrm{M}\right)$ after white light irradiation for different times. (b) Plot of relative PL intensity $\left(I / I_{0}\right)$ at $525 \mathrm{~nm}$ versus the irradiation time. 

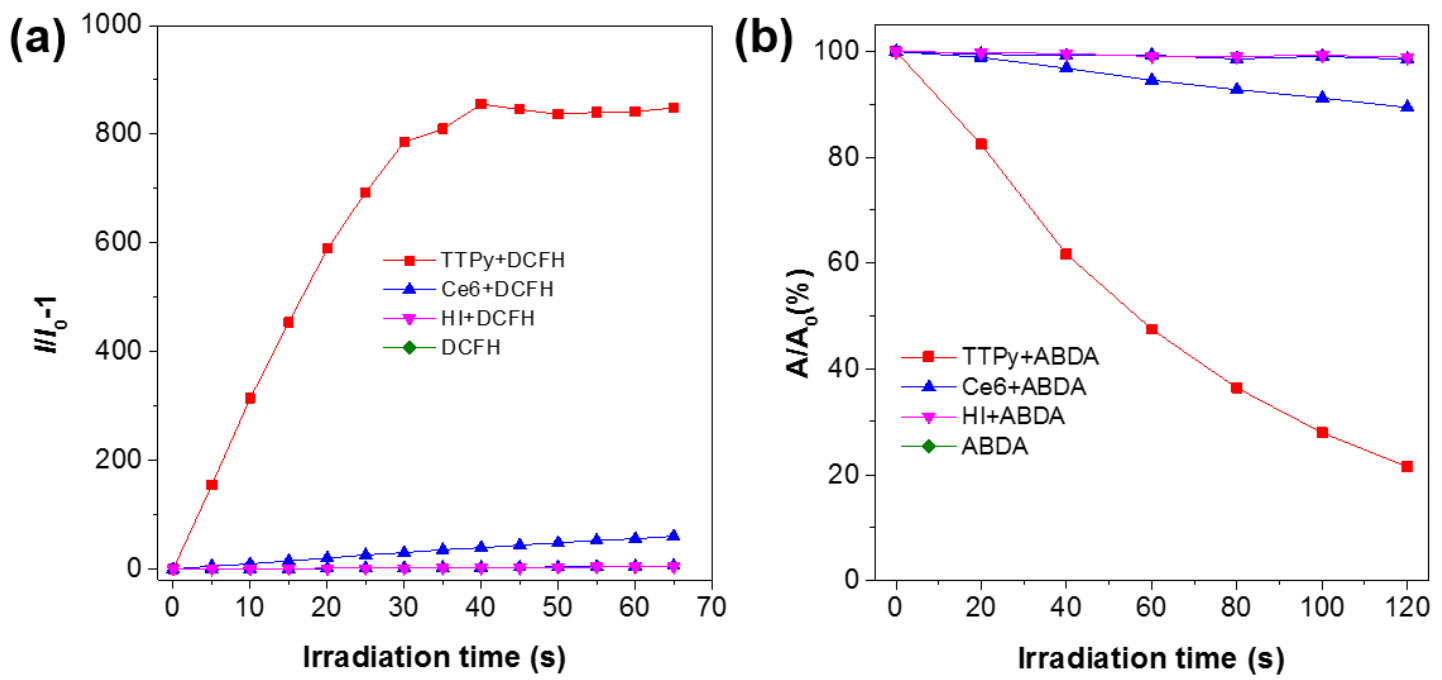

Figure S26. ROS generation of TTPy, HI and Ce6. (a) ROS generation of TTPy, HI and Ce6 $\left(1 \times 10^{-6} \mathrm{M}\right)$ upon white light irradiation using DCFH as indicator. (b) Decomposition rates of ABDA in the presence of TTPy, HI and Ce $6\left(5 \times 10^{-6} \mathrm{M}\right)$ under light irradiation, where $\mathrm{A}_{0}$ and $\mathrm{A}$ are the absorbance of $\mathrm{ABDA}$ at 378 $\mathrm{nm}$.
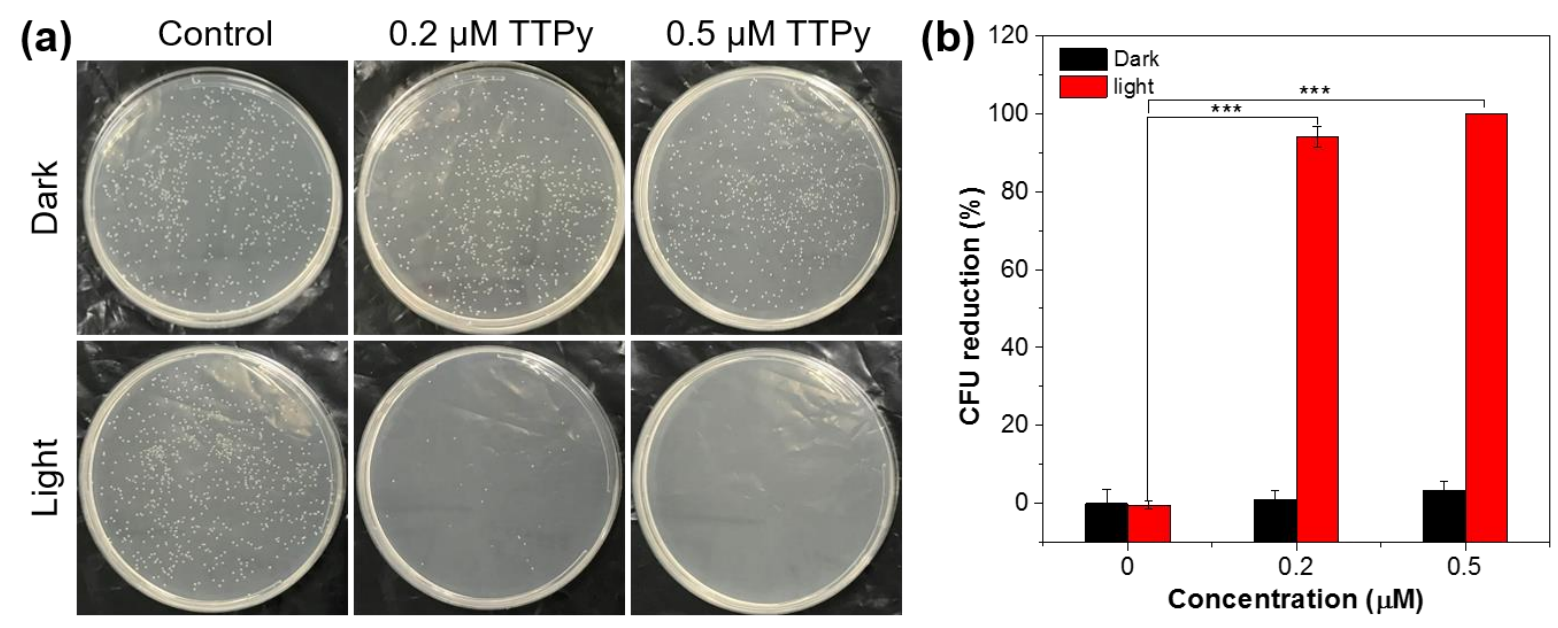

Figure S27. Photodynamic antibacterial activity of TTPy on S. epidermidis. Photographs of the agar plates (a) and CFU reduction (b) of S. epidermidis with or without TTPy and white light $\left.(60 \mathrm{~mW} \mathrm{~cm})^{-2}\right)$ treatment. Error bars, mean \pm s.d. $(\mathrm{n}=3) .{ }^{* * *} \mathrm{P}<0.001$, unpaired Student's t-test (two-tailed). 

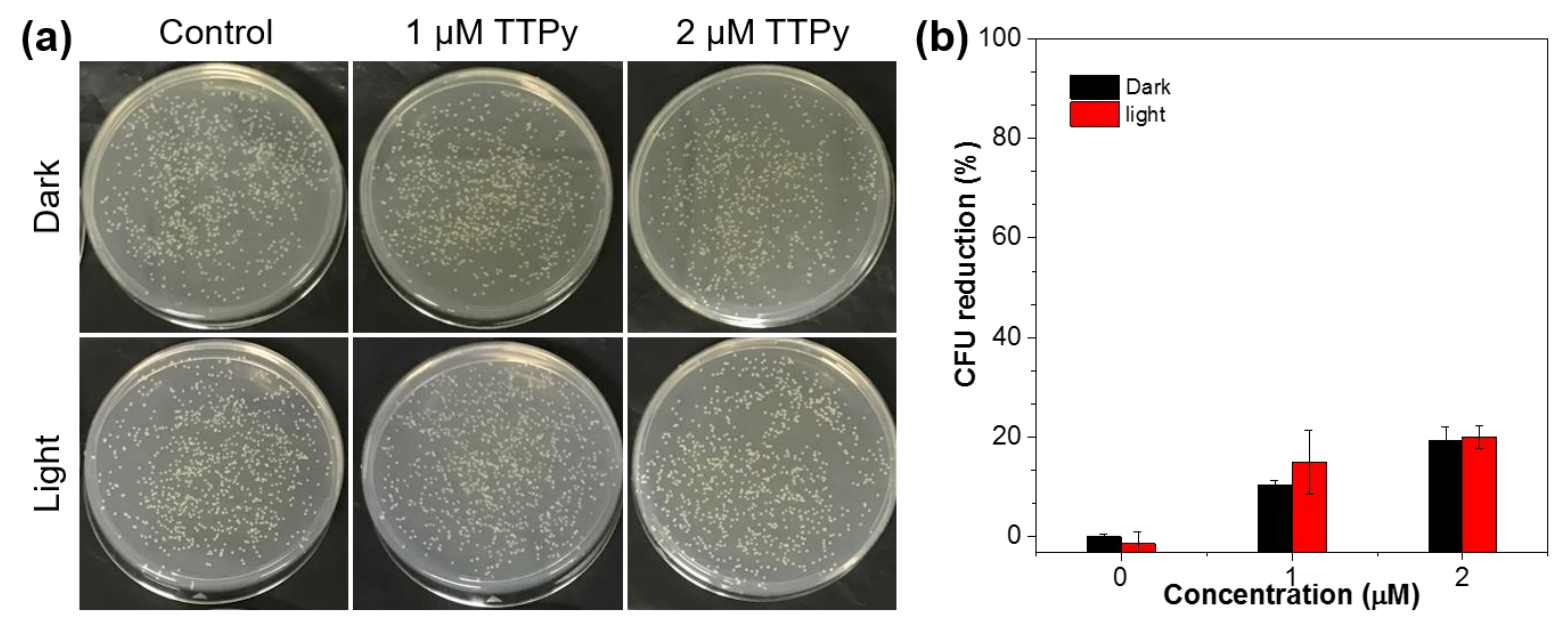

Figure S28. Photodynamic antibacterial activity of HI on S. aureus. Photographs of the agar plates (a) and CFU reduction (b) of S. aureus with or without $\mathrm{HI}$ and white light $\left(60 \mathrm{~mW} \mathrm{~cm}^{-2}\right)$ treatment.
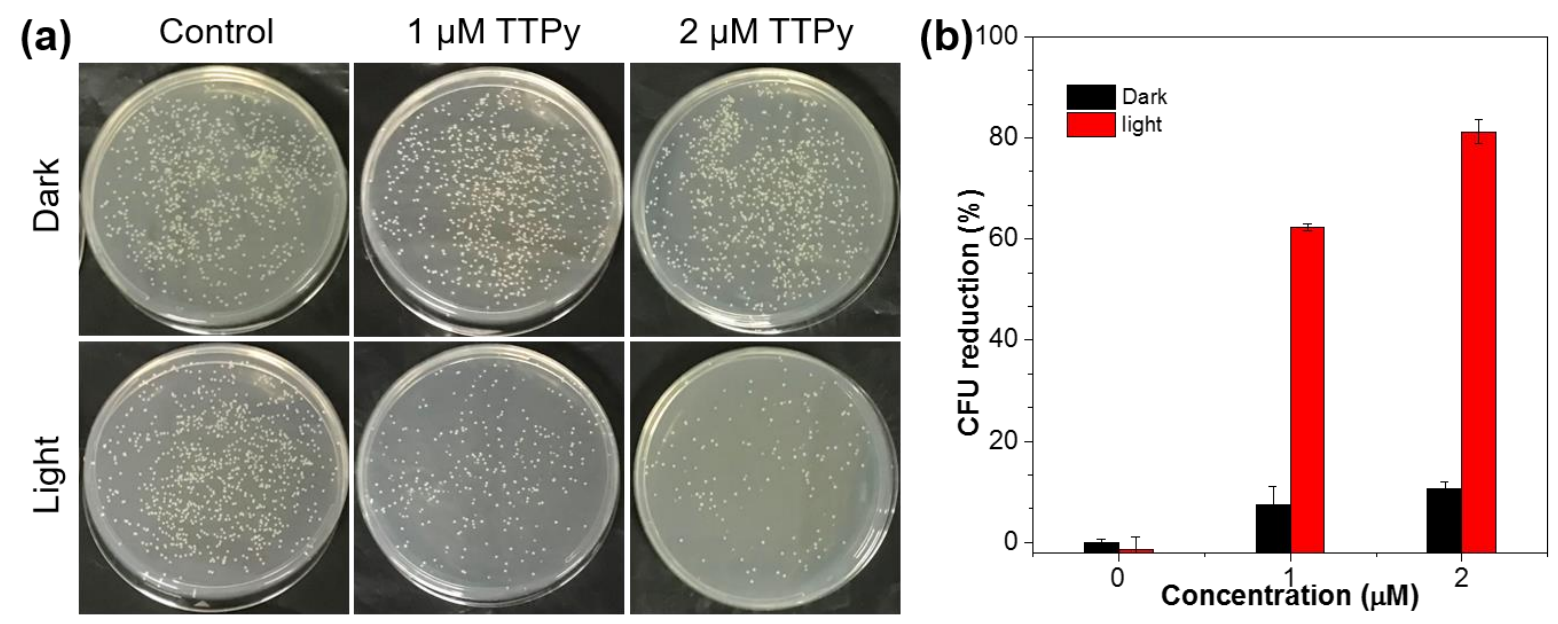

Figure S29. Photodynamic antibacterial activity of Ce6 on S. aureus. Photographs of the agar plates (a) and CFU reduction (b) of S. aureus with or without $\mathrm{Ce} 6$ and white light $\left(60 \mathrm{~mW} \mathrm{~cm}^{-2}\right)$ treatment. 
Table S1. Properties of AIEgens.

\begin{tabular}{cccccccccccc}
\hline \multirow{2}{*}{ AIEgens } & $\begin{array}{c}\lambda_{\text {abs }} \\
(\mathrm{nm})^{\mathrm{a})}\end{array}$ & $\begin{array}{c}\lambda_{\text {em, aggr. }} \\
(\mathrm{nm})^{\mathrm{b})}\end{array}$ & $\begin{array}{c}\lambda_{\text {em, solid }} \\
(\mathrm{nm})^{\mathrm{c})}\end{array}$ & $\alpha_{\mathrm{AIE}}^{\mathrm{d})}$ & $\begin{array}{c}\Phi_{\text {Soln. }} \\
(\%)^{\mathrm{e})}\end{array}$ & $\begin{array}{c}\Phi_{\text {solid }} \\
(\%)^{\mathrm{f})}\end{array}$ & $\begin{array}{c}\tau(\mathrm{ns})^{\mathrm{g})} \\
\mathrm{Clog} \mathrm{P}^{\mathrm{h})}\end{array}$ & $\begin{array}{l}\Delta E_{\mathrm{H}-\mathrm{L}} \\
(\mathrm{eV})^{\mathrm{i})}\end{array}$ & $\begin{array}{c}\Delta E_{\mathrm{S}-\mathrm{T}} \\
(\mathrm{eV})^{\mathrm{j})}\end{array}$ & $\begin{array}{c}\mathrm{CAC} \\
(\mu \mathrm{M})^{\mathrm{k})}\end{array}$ \\
\hline TPy & 458 & 618 & 602 & 16.1 & 0.2 & 4.7 & 3.88 & 2.08 & 2.56 & 0.81 & 2.4870 \\
TPPy & 427 & 645 & 615 & 31.8 & 0.3 & 7.6 & 3.53 & 3.97 & 2.37 & 0.73 & 4.3217 \\
TTPy & 478 & 665 & 658 & 24.0 & 0.5 & 9.6 & 2.42 & 3.85 & 2.21 & 0.57 & 3.7506 \\
MeOTTPy & 500 & 664 & 691 & 8.2 & 0.2 & 2.9 & 0.88 & 3.81 & 2.02 & 0.61 & 2.2478 \\
TPE-TTPy & 484 & 665 & 685 & 13.8 & 0.2 & 4.9 & 0.95 & 9.02 & 2.13 & 0.49 & 1.8304 \\
\hline
\end{tabular}

a) Absorption maximum in DMSO solution; ${ }^{b}$ Emission maximum in aggregate state; ${ }^{c)}$ Emission maximum in solid state; ${ }^{\mathrm{d})} \alpha_{\mathrm{AIE}}=I_{\text {aggr,max }} / I_{\text {soln. }}{ }^{\mathrm{e})}$ Fluorescence quantum yield of AIEgens in DMSO

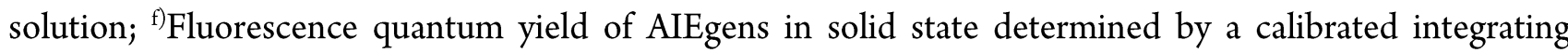
sphere; ${ }^{\mathrm{g}}$ Lifetime of AIEgens; ${ }^{\mathrm{h}}$ The calculated $\log \mathrm{P}$ (n-octanol/water partition coefficient) of AIEgens estimated by the software ChemBioDraw $\left.14.0 ;{ }^{i}\right)$ The value of HOMO-LUMO energy gap of AIEgens; ${ }^{\text {j) }}$ The value of singlet-triplet energy gap of AIEgens; ${ }^{k}$ The critical aggregation concentration (CAC) value of AIEgens.

\section{References}

(1) Xu, W.; Lee, M.; Zhang, Z.; Sung, H.; Williams, I.; Kwok, R. T. K.; Lam, J. W. Y.; Wang, D.; Tang, B. Z. Facile Synthesis of AIEgens with Wide Color Tunability for Cellular Imaging and Therapy. Chem. Sci. 2019, $10,3494-3501$.

(2) Qin, W.; Li, K.; Feng, G.; Li, M.; Yang, Z.; Liu, B.; Tang, B. Z. Bright and Photostable Organic Fluorescent Dots with Aggregation-Induced Emission Characteristics for Noninvasive Long-Term Cell Imaging. Adv. Funct. Mater. 2014, 24, 635-643.

(3) Zhu, Y.; Xu, C.; Zhang, N.; Ding, X.; Yu, B.; Xu, F., Polycationic Synergistic Antibacterial Agents with Multiple Functional Components for Efficient Anti-Infective Therapy. Adv. Funct. Mater. 2018, 28, 170670914.

(4) Wang, D.; Lee, M. M. S.; Shan, G.; Kwok, R. T. K.; Lam, J. W. Y.; Su, H.; Cai, Y.; and Tang, B. Z. Highly Efficient Photosensitizers with Far-Red/Near-Infrared Aggregation-Induced Emission for in Vitro and in Vivo Cancer Theranostics. Adv. Mater. 2018, 30, 1802105. 